\title{
SMOS-derived thin sea ice thickness: algorithm baseline, product specifications and initial verification
}

\author{
X. Tian-Kunze ${ }^{1}$, L. Kaleschke ${ }^{1}$, N. Maaß ${ }^{1}$, M. Mäkynen ${ }^{2}$, N. Serra ${ }^{1}$, M. Drusch ${ }^{3}$, and T. Krumpen ${ }^{4}$ \\ ${ }^{1}$ Institute of Oceanography, University of Hamburg, Bundesstraße 53, 20146 Hamburg, Germany \\ ${ }^{2}$ Finnish Meteorological Institute, Erik Palmenin aukio 1, 00560 Helsinki, Finland \\ ${ }^{3}$ European Space Agency, ESA-ESTEC, 2200 AG Noordwijk, the Netherlands \\ ${ }^{4}$ Alfred Wegener Institute for Polar and Marine Research, Bussestraße 24, 27570 Bremerhaven, Germany \\ Correspondence to: X. Tian-Kunze (xiangshan.tian-kunze@zmaw.de)
}

Received: 21 November 2013 - Published in The Cryosphere Discuss.: 6 December 2013

Revised: 4 April 2014 - Accepted: 10 April 2014 - Published: 27 May 2014

\begin{abstract}
Following the launch of ESA's Soil Moisture and Ocean Salinity (SMOS) mission, it has been shown that brightness temperatures at a low microwave frequency of $1.4 \mathrm{GHz}$ (L-band) are sensitive to sea ice properties. In the first demonstration study, sea ice thickness up to $50 \mathrm{~cm}$ has been derived using a semi-empirical algorithm with constant tie-points. Here, we introduce a novel iterative retrieval algorithm that is based on a thermodynamic sea ice model and a three-layer radiative transfer model, which explicitly takes variations of ice temperature and ice salinity into account. In addition, ice thickness variations within the SMOS spatial resolution are considered through a statistical thickness distribution function derived from high-resolution ice thickness measurements from NASA's Operation IceBridge campaign. This new algorithm has been used for the continuous operational production of a SMOS-based sea ice thickness data set from 2010 on. The data set is compared to and validated with estimates from assimilation systems, remote sensing data, and airborne electromagnetic sounding data. The comparisons show that the new retrieval algorithm has a considerably better agreement with the validation data and delivers a more realistic Arctic-wide ice thickness distribution than the algorithm used in the previous study (Kaleschke et al., 2012).
\end{abstract}

\section{Introduction}

Satellite-based observation of ice thickness is still very challenging. The first satellite-borne observations of ice thickness were conducted with satellite radar altimeters carried on European Remote Sensing satellites (ERS-1 and ERS2) (Laxon et al., 2003) and thermal imagery from the Advanced Very High Resolution Radiometer (AVHRR) (Yu and Rothrock, 1996; Drucker et al., 2003). These early radar altimeter observations were followed by the ICESat laser altimeter from 2003 to 2009 (Kwok and Cunningham, 2008) and, since 2011, by the CryoSat- 2 radar altimeter (Laxon et al., 2013). The radar and laser altimeters have large uncertainties for ice thickness less than $1 \mathrm{~m}$ (Laxon et al., 2003; Kwok and Cunningham, 2008). Therefore, they are more suitable for the detection of thick ice. The altimeter ice thickness charts typically have a one month temporal resolution and a $25-100 \mathrm{~km}$ spatial resolution.

Thin ice thickness up to about $0.5 \mathrm{~m}$ with $1 \mathrm{~km}$ spatial resolution can be estimated with thermal imagery, using the ice surface temperature $\left(T_{\mathrm{S}}\right)$ together with atmospheric forcing data and an ice surface heat balance equation ( $\mathrm{Yu}$ and Rothrock, 1996; Maekynen et al., 2013). The major drawback with the $T_{\mathrm{S}}$-based thickness retrieval is the requirement for cloud-free conditions, thus there may be long temporal gaps in the thickness chart coverage over a region of interest. In addition, discriminating clear sky from clouds is difficult in winter nighttime conditions (Frey et al., 2008). For the ice thickness retrieval, an estimation of snow thickness on 
thin sea ice is needed. Since in situ measurements of snow thickness are seriously lacking in the Arctic, snow thickness from climatology (Warren et al., 1999) or from a thermodynamic sea ice model forced with numerical weather prediction model data (Launiainen and Cheng, 1998) can be used. Typically, snow thickness uncertainty is one of the main factors determining the uncertainty of the retrieved ice thickness (Yu and Rothrock, 1996; Wang et al., 2010).

Passive microwave radiometer data from the Special Sensor Microwave Imager (SSM/I) (37 and $85.5 \mathrm{GHz}$ channels) and Advanced Microwave Scanning Radiometer-Earth Observing System (AMSR-E) (36.5 and 89 GHz channels) sensors have been used to estimate the thickness of thin ice to 10-20 cm (Martin et al., 2005; Tamura et al., 2007; Nihashi et al., 2009; Tamura and Ohshima, 2011; Singh et al., 2011). The spatial resolution of the radiometer-based thin ice thickness charts $(6.25$ to $25 \mathrm{~km})$ is much coarser than that from thermal imagery, but daily Arctic and Antarctic coverage is possible. The thin ice thickness retrieval algorithms are linear or exponential regression equations between polarization ratios (PR) or the $\mathrm{V}$ - to $\mathrm{H}$-polarization ratios $(\mathrm{R})$ and AVHRR or Moderate Resolution Imaging Spectroradiometer (MODIS) thicknesses. Naoki et al. (2008) suggested that the observed decrease of near ice surface salinity as a function of ice thickness, which results in the modification of the ice dielectric properties and further ice emission (i.e., brightness temperatures), is the main reason for the observed relationship between brightness temperature and ice thickness. In addition, the relationship between brightness temperature and ice thickness is more pronounced for $\mathrm{H}$-polarization and for a lower frequency (e.g., 10.7 GHz). Nihashi et al. (2009) found that PR at $37 \mathrm{GHz}$ cannot detect thin ice when it is covered with snow. An analysis of ship-borne radiometer data at 19,37 , and $85 \mathrm{GHz}$ over various thin ice types indicated that a limitation in the thin ice thickness estimation can be attributed to the presence of snow or dense frost flower coverage $(>60 \%)$ on the ice surface (Hwang et al., 2007).

The Soil Moisture and Ocean Salinity (SMOS) mission of the European Space Agency (ESA) was launched in November 2009, and for the first time, globally measures Earth's radiation at a frequency of $1.4 \mathrm{GHz}$ in the L-band (Mecklenburg et al., 2012). The spatial resolution varies from about $35 \mathrm{~km}$ to more than $50 \mathrm{~km}$. Besides soil moisture and ocean salinity information, for which SMOS was originally designed, L-band radiometry on SMOS can also be used to obtain sea ice thickness, which is due to its large penetration depth in sea ice (Kaleschke et al., 2010, 2012). The measured L-band brightness temperature mainly depends on the ice concentration, the molecular temperatures of the sea and the ice, and their emissivities (Menashi et al., 1993; Kaleschke et al., 2010). Sea ice emissivity depends on the microphysical sea ice structure, but inhomogeneities, like brine pockets and air bubbles, are much smaller than the SMOS wavelength of $21 \mathrm{~cm}$ (Kaleschke et al., 2010, 2012). Therefore, we can consider sea ice as a homogeneous medium and ignore vol- ume scattering. The modeled sea ice emissivity used for the present study mainly depends on ice thickness, ice temperature, and ice salinity (Kaleschke et al., 2010).

In contrast to ICESat and CryoSat-2 measurements, SMOS-derived ice thickness has a lower uncertainty in the thin ice range, but an exponentially increasing uncertainty for ice thickness thicker than $0.5 \mathrm{~m}$. In our study, we consider ice thickness less than $50 \mathrm{~cm}$ as thin ice. SMOS-derived ice thickness can thus complement the measurements from CryoSat-2 to achieve Arctic-wide sea ice thickness estimations (Kaleschke et al., 2010, 2012).

The semi-empirical SMOS ice thickness retrieval algorithm applied previously in Kaleschke et al. (2012) (hereinafter Algorithm I) is

$\mathrm{TB}\left(d_{\text {ice }}\right)=T_{1}-\left(T_{1}-T_{0}\right) e^{-\gamma d_{\text {ice }}}$,

where $d_{\text {ice }}$ is the ice thickness, $T_{1}$ and $T_{0}$ are two constant tie points, which were estimated from the observed SMOS brightness temperatures over open water and thick first year ice during the freezing period of 2010 in the Arctic, and $\gamma$ is a constant attenuation factor, which was derived from a sea ice radiation model (Menashi et al., 1993) for a representative bulk ice temperature and salinity in the Arctic.

The advantage of Algorithm I is the retrieval of ice thickness from the brightness temperature (TB) without any auxiliary data set. However, the TB measured by an L-band radiometer over sea ice depends on the dielectric properties of sea ice, which are functions of ice temperature and ice salinity (Kaleschke et al., 2010). Although the change of TB caused by the sea ice thickness variation is much larger than that caused by the variation of ice temperature and ice salinity, the typical variability of these two parameters in the Arctic can induce up to $30 \mathrm{~K}$ difference in TB (Kaleschke et al., 2012). This means, the assumption of constant retrieval parameters could cause considerable errors in regions where these parameters strongly differ from the assumed constant values.

Ice temperature and ice salinity measurements are rare and they are not continuously available on a daily basis in the Arctic. An alternative solution is therefore to derive these two parameters from auxiliary data during the sea ice thickness retrieval. Under the assumption of thermal equilibrium, the surface ice temperature can be estimated from the surface air temperature. For simplification, we ignore the heat capacity of ice and assume that the ice layer reacts rapidly to changes in air temperature. Maaß (2013a) estimated that a thin ice layer with a thickness of $50 \mathrm{~cm}$ needs less than $2 \mathrm{~h}$ to re-establish a linear temperature gradient within the ice. We apply our retrieval only for the period from October to April for the Northern Hemisphere, which allows us to ignore melting effects on the surface. Since we calculate daily averaged sea ice thickness of thin ice, it is a reasonable assumption to consider that the ice surface temperature is at equilibrium with the surface heat balance. Therefore, we use a heat flux balance equation and use the surface air 
temperature from atmospheric reanalysis data as a boundary condition. Ice salinity can be estimated from the underlying sea surface salinity (SSS) with an empirical function (Ryvlin, 1974). With these two parameters, we can calculate brightness temperature with the sea ice radiation model (Menashi et al., 1993). However, both ice temperature and ice salinity are, in turn, functions of ice thickness. Thus, we need to apply a linear approximation method to simultaneously retrieve ice thickness and estimate suitable ice temperature and salinity values. This algorithm is called Algorithm II hereinafter.

In the radiation model of Menashi et al. (1993), a plane ice layer is assumed. However, natural sea ice exhibits a statistical thickness distribution within the spatial resolution of SMOS, due to dynamic-thermodynamic growth and deformation processes (Bartels-Rausch et al., 2012). The brightness temperature measured by SMOS is a mixture of brightness temperatures from different ice thicknesses, and possibly open water. As SMOS brightness temperature is more sensitive to ice thicknesses less than $0.5 \mathrm{~m}$ (Kaleschke et al., 2012), SMOS-derived ice thickness depends on the thin ice part of the ice thickness distribution within the spatial resolution, while the contribution of the thicker ice part cannot be quantified due to the limited penetration depth. Thus, the overall mean thickness for a mixture of thin and thick ice can only be estimated in a statistical sense if the thickness distribution function is known. A possible solution for the corresponding underestimation of ice thickness is to correct the retrieved ice thickness, using an ice thickness distribution function. The correction of ice thickness retrieved from Algorithm II using this function is called Algorithm II* in this study.

Here, we compare the three different SMOS ice thickness retrieval algorithms for the Arctic. The plane layer ice thicknesses retrieved from Algorithm I and II are compared with independent data to examine if the method that considers variable ice temperature and ice salinity improves the accuracy of the ice thickness retrieval. Thereafter, sea ice thickness uncertainty is estimated on a daily basis, using the better algorithm. The growth of the sea ice cover, as seen by SMOS during a freezing period in the Arctic, is also discussed.

The paper is structured as follows. In Sect. 2, we describe the SMOS brightness temperature and the auxiliary data sets. The baseline of Algorithm II is described in Sect. 3 . In Sect. 4, we discuss the uncertainties and biases of the retrieved ice thickness. After that we present, in Sect. 5, our method to correct the retrieved ice thickness based on the assumption of a plane ice layer with an empirically determined ice thickness distribution function. The comparison of ice thicknesses retrieved from different algorithms is discussed in Sect. 6. Ice thickness growth and distribution, as seen by SMOS during the freeze-up period in the Arctic are shown in Sect. 7. A further comparison of SMOS-derived ice thickness with that derived from MODIS in the Kara Sea is presented in Sect. 8. Finally, a summary and discussion are given in Sect. 9.

\section{Data}

Three different data sets are used for the retrieval of sea ice thickness in Algorithm II. The basis of the retrieval is the brightness temperature measured by the SMOS L-band radiometer. This data set is described in Sect. 2.1. For the estimation of bulk ice temperature $\left(T_{\text {ice }}\right)$ we use surface air temperature $\left(T_{\mathrm{a}}\right)$ from Japanese $25 \mathrm{yr}$ Reanalysis (JRA-25) data, which are described in Sect. 2.2. The SSS climatology, which is used for the calculation of bulk ice salinity $\left(S_{\text {ice }}\right)$ is presented in Sect. 2.3. Finally, for the verification of the SMOS ice thickness, MODIS ice thickness charts over the Kara Sea are presented in Sect. 2.4.

\subsection{SMOS brightness temperature data}

\subsubsection{L1C data}

The SMOS payload Microwave Imaging Radiometer using Aperture Synthesis (MIRAS) measures in the L-band brightness temperatures in full polarization, with incidence angles ranging from $0^{\circ}$ to $65^{\circ}$. All four Stokes parameters are obtained (Kerr et al., 2001). It has global coverage every three days (Kerr et al., 2001), whereas daily coverage up to $85^{\circ}$ latitude can be expected in the polar regions. Brightness temperature is taken every $1.2 \mathrm{~s}$ by hexagon-like, two-dimensional snapshots, which have a spatial dimension of about $1200 \mathrm{~km}$ across (Kerr et al., 2001). The geometric distribution of incidence angles and radiometric accuracy within the alias-free areas of a snapshot (Camps et al., 2005) is shown in Fig. 1. The spatial resolution varies from about $35 \mathrm{~km}$ at nadir view to more than $50 \mathrm{~km}$ at incidence angles higher than $60^{\circ}$. Each snapshot measures one or two of the Stokes components in the antenna reference frame. Horizontally and vertically polarized brightness temperatures are measured by separate snapshots.

The SMOS L1C data are geolocated in an equal-area Discrete Global Grid (DGG) system called ISEA 4H9 (Icosahedral Snyder Equal Area projection with aperture 4, resolution 9 and shape of cells as hexagon) (Pinori et al., 2008). ISEA $4 \mathrm{H} 9$ provides a uniform inter-cell distance of $15 \mathrm{~km}$. Most of the pixels in the Arctic are covered by several overflights during one day. Therefore, for our daily product, at each DGG grid point we collect all brightness temperatures measured during one day, together with other information, like the incidence angles.

\subsubsection{Radio frequency interference}

SMOS measurements are partly influenced by Radio Frequency Interference (RFI), which comes from radar, TV, and radio transmission (Mecklenburg et al., 2012). The detection of RFI sources and the mitigation of RFI influence are critical steps for the further retrieval of geophysical parameters. The RFI influence depends on the incidence angle, polarization, and ascending or descending modes of the satellite 


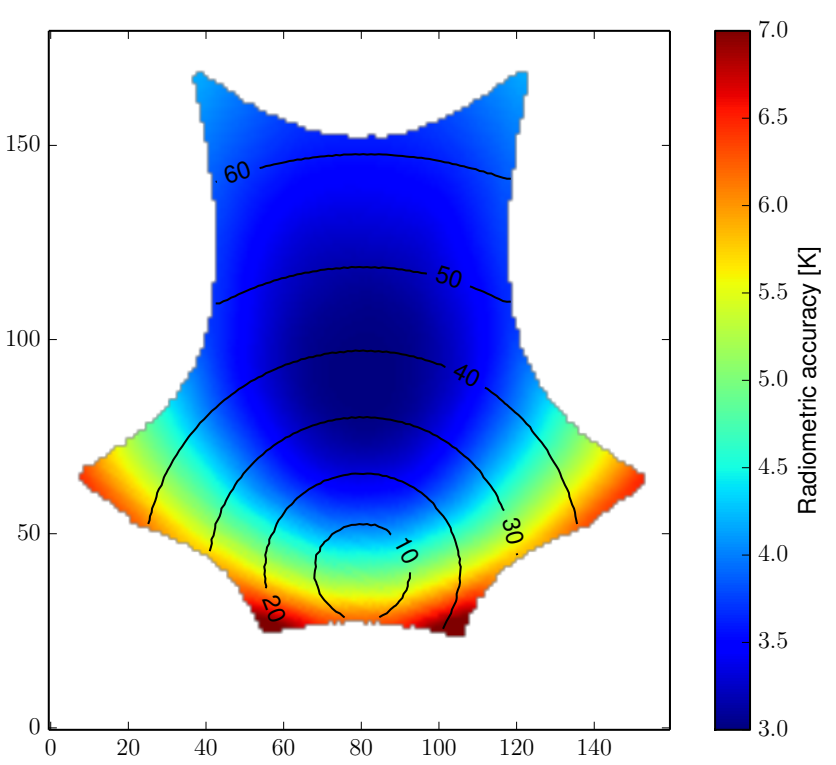

Figure 1. Distribution of radiometric accuracy within a typical snapshot with incidence angles (degrees) as contour lines. To avoid the patchy distribution of DGG pixels within one snapshot, we overlaid 100 consecutive snapshots after axis transformation. After that, the radiometric accuracy and incidence angles are interpolated with $10 \mathrm{~km}$ spatial grid resolution.

(Camps et al., 2010). A closer look into RFI-contaminated snapshots shows that RFI can either completely or partly destroy a snapshot (Camps et al., 2010). For simplification, we apply a threshold value for both horizontally and vertically polarized brightness temperatures. If either of them exceeds $300 \mathrm{~K}$ within one snapshot, this snapshot is considered RFI contaminated. Brightness temperatures higher than $300 \mathrm{~K}$ can not be expected in the Arctic and Antarctic.

According to this RFI filter, strongly RFI-affected regions are the region northeast of Greenland and parts of the Canadian Arctic Archipelago. Figure 2 shows the RFI-induced data loss based on our RFI filter. The data loss in the figure is defined as the ratio between the number of RFI-contaminated measurements and the number of total measurements. As can be seen from Fig. 2, the status of RFI in the Arctic region has improved much since 2010 .

\subsubsection{Brightness temperature intensity}

Over sea ice, the first Stokes parameter (intensity) is almost independent of incidence angle in the incidence angle range of $0-40^{\circ}$ (Fig. 3). The intensity is the average of the horizontally and vertically polarized brightness temperatures, equal to $0.5\left(\mathrm{~TB}_{\mathrm{h}}+\mathrm{TB}_{\mathrm{v}}\right)$. The intensity is independent of both geometric and Faraday rotations, and robust to instrumental and geophysical errors (Camps et al., 2005). We can avoid additional uncertainties caused by the transformation from the antenna reference frame to the Earth reference frame by using the intensity. Since each snapshot measures either hor- izontally or vertically polarized brightness temperature, we use consecutive snapshots with an acquisition time difference of less than $2.5 \mathrm{~s}$ to calculate the intensity. The advantage of using near-nadir measurements is the smaller footprint associated with low incidence angles. Furthermore, by using the whole incidence angle range of $0-40^{\circ}$ we get more than 100 brightness temperature measurements per day for most of the DGG grid points in the Arctic; and by averaging over numerous measurements we can significantly reduce the uncertainty of the retrieval. However, by averaging all the measurements, we partly reduce the geophysical and temporal variability. The daily averaged brightness temperature intensities in the Arctic and in the Antarctic are interpolated with a nearest-neighbor algorithm and gridded into the National Snow and Ice Data Center (NSIDC) polar stereographic projection with a grid resolution of $12.5 \mathrm{~km}$ (https://nsidc.org/ data/polar_stereo/ps_grids.html). We use this grid resolution because other products that we use as auxiliary data in the retrieval are also given in this resolution. We call this product L3B brightness temperature. In the following we use TB to indicate the daily averaged brightness temperature intensity. The data are processed with about $24 \mathrm{~h}$ latency for both hemispheres, and cover a period since January 2010. The L3B TBs are the basis of our sea ice thickness retrieval with Algorithm I and II and can be obtained from icdc.zmaw.de.

\subsection{JRA-25 reanalysis data}

For estimating the ice surface temperature, we extract the $2 \mathrm{~m}$ surface air temperature and the $10 \mathrm{~m}$ wind velocity data from JRA-25 atmospheric reanalysis data and interpolate them into the polar stereographic projection with $12.5 \mathrm{~km}$ grid resolution. JRA-25 reanalysis data provide various physical variables with $1.125^{\circ}$ resolution every six hours. The data have been produced by the Japanese Meteorological Agency (JMA) using the latest numerical analysis and prediction system. JRA-25 covers the period from 1979 to 2004. JRA25 has been transitioned to JMA Climate Data Assimilation System (JCDAS), which takes over JRA-25 after 2005 on a real-time basis using the same assimilation system (Onogi et al., 2007). Various studies have been carried out comparing the JRA-25, ERA40 and National Centers for Environmental Prediction (NCEP) data sets. Good agreement was found between JRA-25 and ERA40 (Onogi et al., 2007).

\subsection{Sea surface salinity climatology}

Sea surface salinity information is needed to estimate the bulk ice salinity, which is an input parameter of the radiation model of sea ice. There are global sea surface salinity products derived from SMOS satellite data. Ocean salinity is one of the two applications SMOS was originally designed for. However, SMOS-derived ocean salinity is not available in ice-covered regions of the Arctic. Thus, we use an SSS 

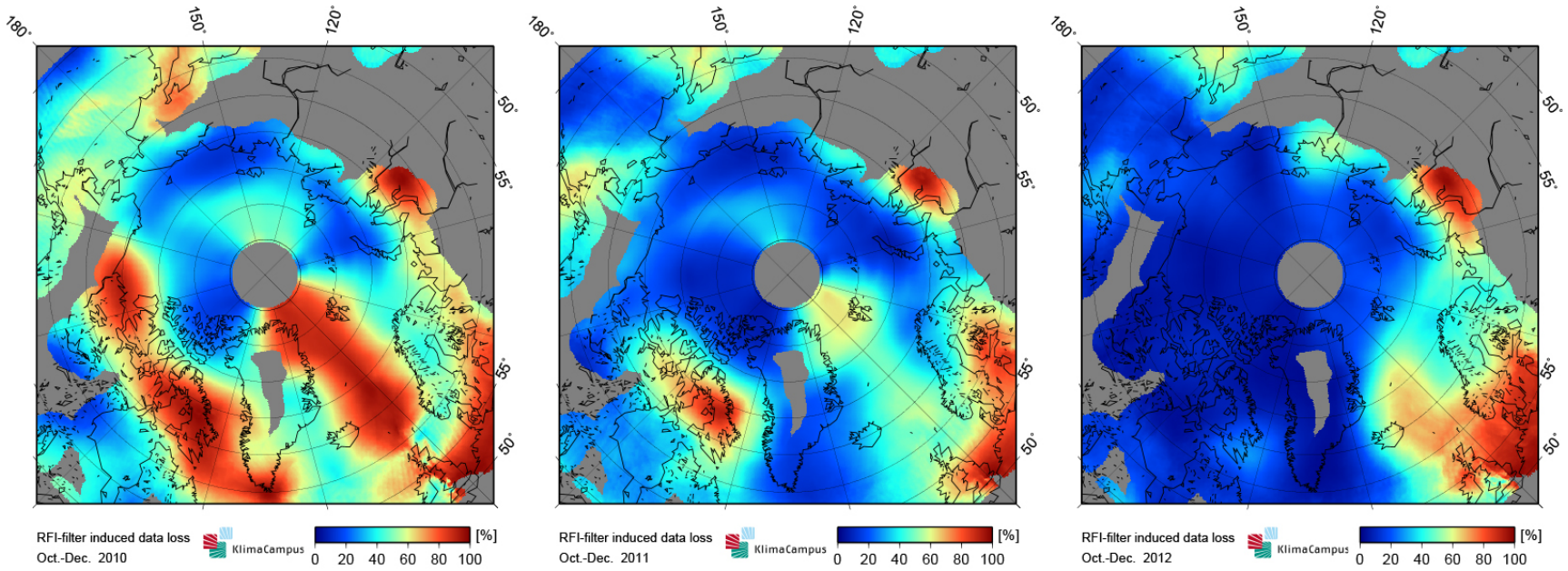

Figure 2. The RFI-induced data loss in the Arctic from 2010 to 2012. The data loss is defined as the ratio between the number of RFIcontaminated measurements and the number of total measurements. A strongly reduced data loss can be observed in 2012 especially in the Canadian Arctic Archipelago compared with the map of 2010.

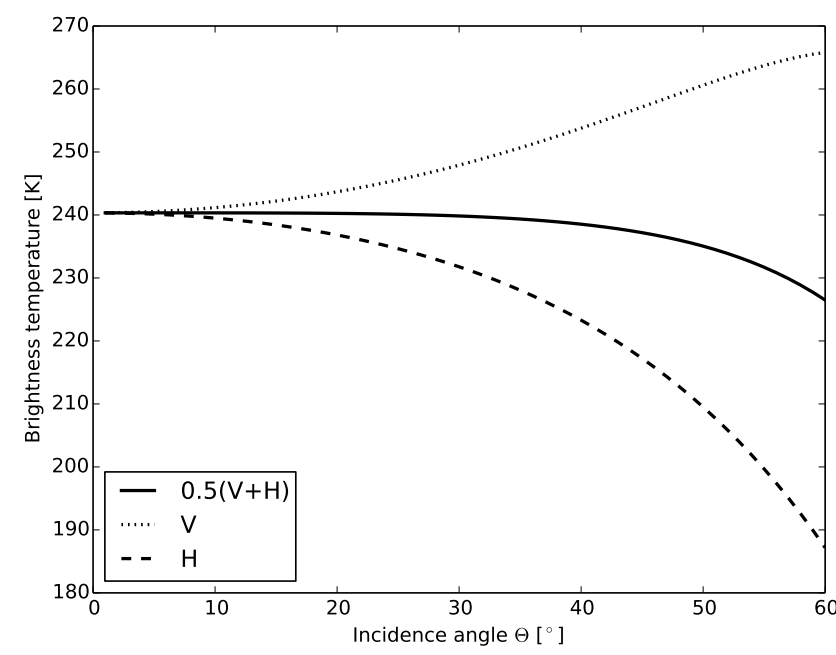

Figure 3. Vertically $(\mathrm{V})$ and horizontally $(\mathrm{H})$ polarized TBs and the first Stokes parameter as a function of incidence angle calculated using a three-layer model for sea ice with a thickness of $d_{\text {ice }}=1 \mathrm{~m}$, a bulk salinity of $S_{\text {ice }}=8 \mathrm{~g} \mathrm{~kg}^{-1}$, and a bulk ice temperature of $T_{\text {ice }}=-7^{\circ} \mathrm{C}$.

climatology based on the output of an ocean-sea ice coupled model.

The SSS data used in this work result from an integration of the MIT General Circulation Model (MITgcm) (Marshall et al., 1997), including interannually varying surface forcing. The model is configured for the Atlantic Ocean north of $33^{\circ} \mathrm{S}$, including all marginal Atlantic seas and the Arctic Ocean and with the Bering Strait as a boundary, and is integrated at the eddy-resolving resolution of approximately $4 \mathrm{~km}$. The vertical resolution of the model varies from $5 \mathrm{~m}$ in the upper ocean to $275 \mathrm{~m}$ in the deep ocean (100 verti- cal levels are used). Bottom topography is interpolated from the ETOPO2 database (Smith and Sandwell, 1997) and initial temperature and salinity conditions from a $8 \mathrm{~km}$ resolution integration of the same model (to achieve a good degree of spin-up), which in turn were obtained from the WOA09 climatology (Locarnini et al., 2010; Antonov et al., 2010). The model is forced at the surface by fluxes of momentum, heat, and freshwater, computed internally in the model with the help of the 6 hourly atmospheric state from the European Centre for Medium-Range Weather Forecasts ERA-Interim reanalysis (Dee et al., 2011) and bulk formula. At the open boundaries, the model is forced by a $1^{\circ}$ resolution global solution. The K-Profile Parameterization (KPP) formulation is used for the parameterization of vertical mixing, with a background vertical viscosity coefficient of $1 \times 10^{-4} \mathrm{~m}^{2} \mathrm{~s}^{-1}$. The vertical diffusion employed amounts to $1 \times 10^{-5} \mathrm{~m}^{2} \mathrm{~s}^{-1}$. Unresolved horizontal mixing uses a biharmonic diffusion/viscosity of $3 \times 10^{9} \mathrm{~m}^{4} \mathrm{~s}^{-1}$. Annually averaged river run-off based on the Fekete et al. (1999) data set is introduced as a virtual salt flux, which is summed at certain coastal grid points (approximately the river mouths) to freshwater forcing, specifically to precipitation (from the ERA reanalysis) minus evaporation (computed in the model). The overall good performance of this model configuration (integrated at $8 \mathrm{~km}$ resolution), assessed through comparisons with in situ measurements, can be found in Serra et al. (2010); Brath et al. (2010); Dmitrenko et al. (2012).

From the model's daily surface salinity output for the years 2002-2009, a "weekly climatology" was produced. This means that for every week in a climatological year, 56 salinity values ( 7 days $\times 8 \mathrm{yr}$ ) were averaged at each location. The resulting climatology has therefore 52 values (52 weeks) at each position. In conclusion, we use a seasonal climatology with weekly resolution, which is here abbreviated to 

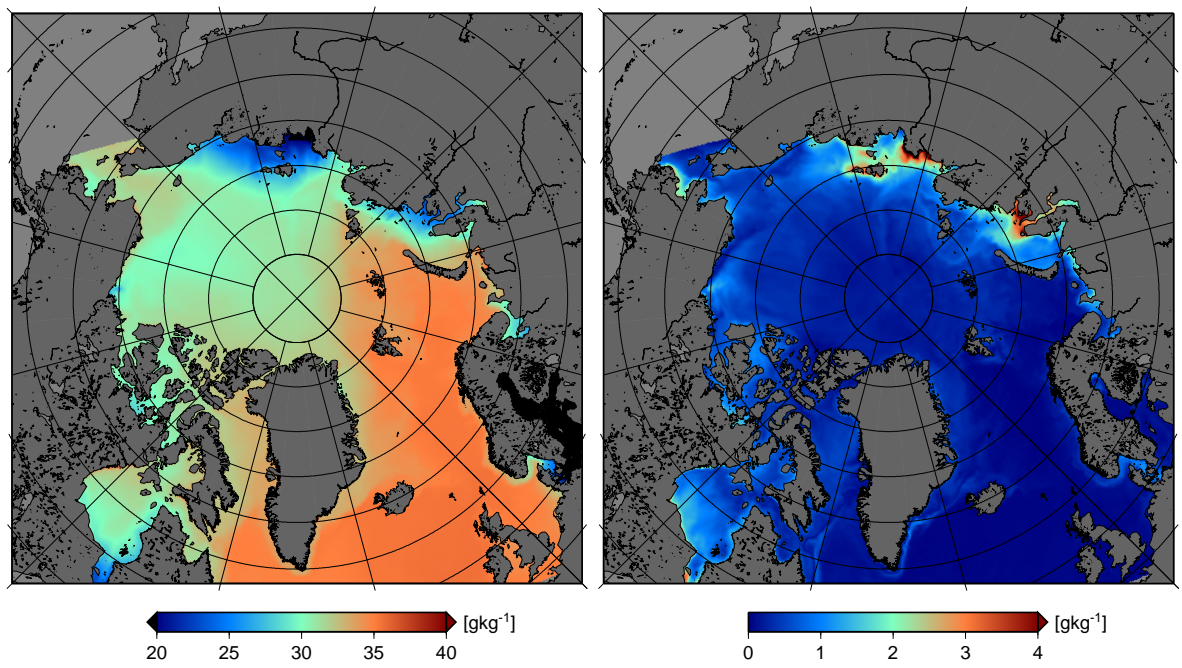

Figure 4. Mean (left map) and standard deviation (right map) of weekly sea surface salinity for the winter period from October to April, based on $8 \mathrm{yr}$ of daily model output.

"weekly climatology". We choose to use a model climatology and not the Polar Science Center Hydrographic Climatology (PHC) (Steele et al., 2001) in order to benefit from the dynamical oceanographic structures realistically resolved in the model, which leads to spatial and seasonal variability of SSS.

Figure 4 shows the mean and standard deviation of weekly SSS from October to April, based on the $8 \mathrm{yr}$ of daily model output. SSS in the Laptev Sea, parts of the Kara Sea, and the Baltic Sea is much lower than that in the central Arctic due to the influence of river run-offs. In contrast, in Baffin Bay, the Greenland Sea, and the Barents Sea, SSS is higher than in the central Arctic. The mean weekly SSS in the Baltic sea varies in the range of $4-10 \mathrm{~g} \mathrm{~kg}^{-1}$, which agrees well with the observed climatology given in Janssen et al. (1999). To calculate Arctic-wide ice thickness distributions, it is important to use the spatially and temporally variable weekly SSS climatology.

\subsection{MODIS ice thickness charts}

MODIS ice thickness charts have been calculated covering an area of $1500 \mathrm{~km} \times 1350 \mathrm{~km}$ over the Kara Sea and the eastern part of the Barents Sea. The derivation of the charts and their uncertainty estimation are described in detail in Maekynen et al. (2013). The total number of charts is 120, and they cover two winters (November to April) in 2009-2011. The spatial resolution of the charts is $1 \mathrm{~km}$, and they show ice thickness from 0 to $99 \mathrm{~cm}$. The external forcing data for solving the ice thickness from the surface heat balance equation come from the numerical weather prediction (NWP) model HIRLAM (HIgh-Resolution Limited Area Model) (Kaellen, 1996; Unden, 2002). Only nighttime MODIS data are employed. Thus, the uncertainties related to the effects of solar shortwave radiation and surface albedo are excluded. For the cloud masking of the MODIS data, in addition to the different cloud tests (Frey et al., 2008), manual methods are also used in order to improve the detection of thin clouds and ice fog. The cloud masking is conducted with $10 \mathrm{~km} \times 10 \mathrm{~km}$ blocks to identify larger cloud-free areas and to reduce errors due to the MODIS-sensor striping effect. In the ice thickness chart calculation, an average snow thickness $\left(h_{\mathrm{s}}\right)$ to ice thickness $\left(h_{\mathrm{i}}\right)$ ratio is used. The thickness of the snow layer is assumed to be

$$
\begin{array}{lr}
h_{\mathrm{s}}=0 \mathrm{~m} & \text { for } d_{\text {ice }}<0.05 \mathrm{~m}, \\
h_{\mathrm{s}}=0.05 \times d_{\text {ice }} & \text { for } 0.05 \mathrm{~m} \leq d_{\text {ice }}<0.2 \mathrm{~m}, \\
h_{\mathrm{s}}=0.09 \times d_{\text {ice }} & \text { for } d_{\text {ice }} \geq 0.2 \mathrm{~m} .
\end{array}
$$

This relationship is based on Doronin (1971) and the Soviet Union's Sever expeditions data (NSIDC, 2004). The typical maximum reliable ice thickness (max $50 \%$ uncertainty) is estimated to be $35-50 \mathrm{~cm}$ under typical weather conditions (air temperature $T_{\mathrm{a}}<-20^{\circ} \mathrm{C}$, wind speed $V_{a}<5 \mathrm{~ms}^{-1}$ ) for the MODIS data (Maekynen et al., 2013). The accuracy is best for the $15-30 \mathrm{~cm}$ thickness range, around $38 \%$. These figures are based on the Monte Carlo method using estimated standard deviations and covariances of the input variables to the thickness retrieval. No in situ data are available for the thickness accuracy estimation. The MODIS ice thickness chart shows ice thickness in the 0 to $99 \mathrm{~cm}$ range, although the upper limit for accurate MODIS-based ice thickness is smaller, $35-50 \mathrm{~cm}$ (Maekynen et al., 2013). Thus, thicknesses larger than $50 \mathrm{~cm}$ only indicate areas of thick ice without accurate thickness estimation. 


\section{Sea ice thickness retrieval Algorithm II}

Algorithm I is described in detail in Kaleschke et al. (2012). We will here introduce the retrieval Algorithm II. As in Algorithm I, we use the daily mean brightness temperature intensity $\mathrm{TB}$ averaged over $0-40^{\circ}$ incidence angle range.

\subsection{The sea ice radiation model}

The basis of the SMOS ice thickness retrievals Algorithm I and II is the sea ice radiation model adapted from Menashi et al. (1993). While for Algorithm I the radiation model is used to calculate the constant attenuation factor $\gamma$ for a representative $T_{\text {ice }}$ and $S_{\text {ice }}$ in the Arctic, in Algorithm II the model is used to calculate TB at variable $T_{\text {ice }}$ and $S_{\text {ice }}$.

The sea ice radiation model consists of a plane ice layer bordered by the underlying sea water and air on the top. The model does not allow adding a snow layer. A snow layer has a twofold effect on the L-band emission. One is the thermodynamic insulation effect, which will be discussed in the following section, the other is the radiative contribution to the overall brightness temperature. To consider the second effect, an elaborate inter-comparison with a multi-layer emission model that includes a snow layer (e.g., Maaß et al., 2013b) would be necessary. The TB over sea ice depends on the dielectric properties of the ice layer, which are a function of brine volume (Vant et al., 1978). The brine volume is a function of $S_{\text {ice }}$ and $T_{\text {ice }}$ (Cox and Weeks, 1983).

For a thin ice layer, the ice temperature gradient within the ice can be assumed to be linear (Maaß, 2013a). Assuming that the water under sea ice is at the freezing point, we can calculate $T_{\text {ice }}$ with $0.5\left(T_{\mathrm{si}}+T_{\mathrm{w}}\right)$, where $T_{\mathrm{si}}$ is the snow-ice interface temperature, and $T_{\mathrm{w}}$ is the freezing sea water temperature. The $T_{\mathrm{si}}$ is calculated with a thermodynamic model with $T_{\mathrm{a}}$ as a boundary condition. The thermodynamic model is presented in the next section.

$S_{\text {ice }}$ is estimated using the empirical function of Ryvlin (1974):

$S_{\text {ice }}=S_{\mathrm{w}}\left(1-S_{\mathrm{R}}\right) e^{-a \sqrt{d_{\text {ice }}}}+S_{\mathrm{R}} S_{\mathrm{w}}$,

where $S_{\mathrm{w}}$ is the SSS, $d_{\text {ice }}$ is the ice thickness (here in $\mathrm{cm}$ ), $S_{\mathrm{R}}$ is the salinity ratio of the bulk ice salinity at the end of the ice growth season, and the SSS, $a$ is the growth rate coefficient, which varies from 0.35 to 0.5 . Ryvlin (1974) suggests using 0.5 for $a$ and 0.13 for $S_{\mathrm{R}}$. However, Kovacs (1996) compares the Ryvlin empirical equation with observed data in the Arctic and suggests using 0.175 for $S_{\mathrm{R}}$ instead of 0.13 . In our model, we use 0.175 for $S_{R}$, which seems to fit better to the observation data of ice salinity in the Arctic. Cox and Weeks (1983) give another empirical relationship between $S_{\text {ice }}$ and $d_{\text {ice }}$ in the Central Arctic. The two empirical relationships have similar values for first year ice and a water salinity of $S_{\mathrm{w}}=31 \mathrm{~g} \mathrm{~kg}^{-1}$ (Kovacs, 1996). The $S_{\text {ice }}$ in Eq. (2) is a function of the underlying SSS. Therefore, we can calculate ice salinity based on the Arctic-wide SSS climatology.

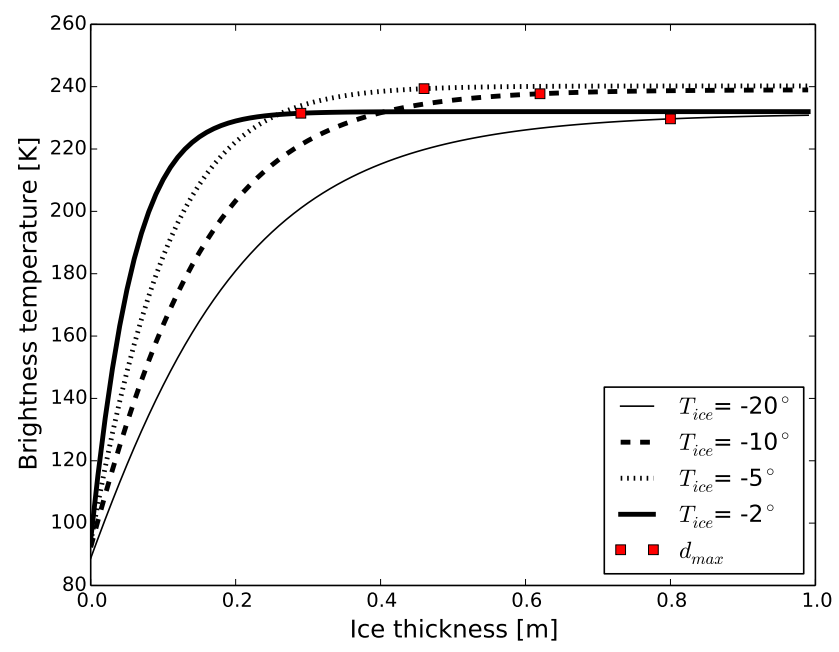

Figure 5. TB as function of $d_{\text {ice }}$ under different $T_{\text {ice }}$, calculated with the sea ice radiation model with a $S_{\text {ice }}$ of $8 \mathrm{~g} \mathrm{~kg}^{-1}$

The ice thickness retrieval with SMOS data is limited by the saturation of TB. We consider TB to reach saturation if the change of TB with $d_{\text {ice }}$ is less than $0.1 \mathrm{~K}$ per $\mathrm{cm}$. Thus, TB of an ice layer with a $T_{\text {ice }}$ of $-2{ }^{\circ} \mathrm{C}$ and a salinity of $8 \mathrm{~g} \mathrm{~kg}^{-1}$ reaches its saturation for ice thicknesses of less than $30 \mathrm{~cm}$, for example. This means that the maximal retrievable ice thickness $d_{\max }$ under warm and saline conditions can be as low as a few centimeters. In contrast, under cold conditions and a low ice salinity, which is typical for coastal regions with river run-off, L-band TB emanates from a thicker ice layer. TB reaches its saturation much more slowly, and $d_{\max }$ can be as high as $1.5 \mathrm{~m}$ (Figs. 5 and 6). Therefore, SMOS ice thickness retrieval is more suitable for cold conditions and low ice salinity. If the ice temperature varies between $-5^{\circ} \mathrm{C}$ and $-10^{\circ} \mathrm{C}$, which can be expected in thin-ice covered areas in the Arctic during the freeze-up period (Perovich and Elder, 2001), the difference of retrieved ice thicknesses can be as high as $20 \mathrm{~cm}$. The influence of ice salinity on the ice thickness retrieval increases with decreasing ice salinity (Maaß, 2013a). For example, under a $T_{\text {ice }}$ of $-10^{\circ} \mathrm{C}$, the $d_{\max }$ at $1 \mathrm{~g} \mathrm{~kg}^{-1} S_{\text {ice }}$ can be twice of that at $5 \mathrm{~g} \mathrm{~kg}^{-1} S_{\text {ice }}$.

\subsection{The thermodynamic model}

In Algorithm II, $T_{\text {ice }}$ is estimated at each step from $d_{\text {ice }}$ and $T_{\mathrm{a}}$. For this purpose, thermal equilibrium is assumed at the surface of the ice layer and heat fluxes are calculated with a thermodynamic model based on Maykut (1986). Although we ignore snow layer in the sea ice radiation model, we consider its thermal insulation effect in the thermodynamic model when we calculate $T_{\text {ice }}$. It is shown in Maaß et al. (2013b) that the impact of a snow layer on the TB is partly caused by its insulation effect on the ice temperature. The insulation effect of a snow layer increases with snow thickness. Linear temperature gradient profiles are assumed for the ice 


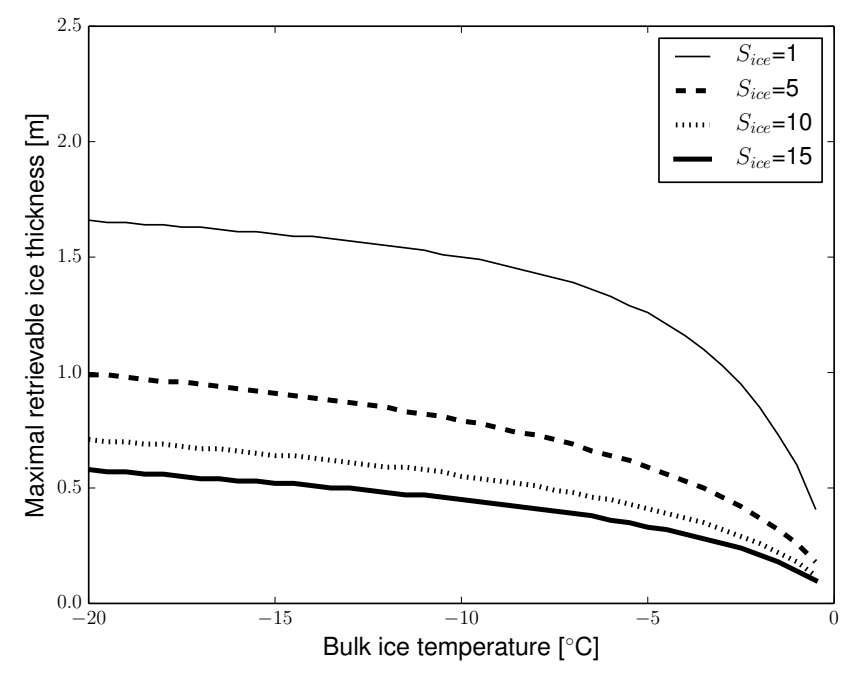

Figure 6. $d_{\text {max }}$ under different $T_{\text {ice }}\left[{ }^{\circ} \mathrm{C}\right]$ and $S_{\text {ice }}\left[\mathrm{g} \mathrm{kg}^{-1}\right]$.

and snow layers in the model. The snow thickness $h_{\mathrm{s}}$ is calculated with $d_{\text {ice }}$ according to the relationship given in Doronin (1971) (see Sect. 2.4).

Under the assumption of thermal equilibrium, the incoming and outgoing heat fluxes compensate each other. During winter season, surface melting can be ignored. Therefore, the heat balance at the surface of a slab ice layer with thickness $d_{\text {ice }}$ and a layer of snow with thickness $h_{\mathrm{s}}$ on top can be described as

$$
(1-\alpha) F_{\mathrm{r}}-I_{0}+F_{\text {Lin }}-F_{\text {Lout }}+F_{\mathrm{s}}+F_{\mathrm{e}}+F_{\mathrm{c}}=0,
$$

where $F_{\mathrm{r}}$ is the incoming shortwave radiation, $\alpha$ is the albedo of the snow/ice layer, $I_{0}$ is the part of the incoming shortwave radiation that is transmitted into the ice, $F_{\mathrm{Lin}}$ is the incoming longwave radiation, $F_{\text {Lout }}$ is the outgoing longwave radiation, $F_{\mathrm{S}}$ is the sensible heat flux, $F_{\mathrm{e}}$ is the latent heat flux, and $F_{\mathrm{c}}$ is the conductive heat flux.

The radiative and turbulent fluxes $(1-\alpha) F_{\mathrm{r}}-I_{0}, F_{\mathrm{Lin}}$, $F_{\text {Lout }}, F_{\mathrm{e}}$, and $F_{\mathrm{s}}$ are calculated as in Maykut (1986). For simplification we assume constant values for the cloud cover $C$, the relative humidity $r$, and the bulk transfer coefficients for sensible and latent heat flux $C_{\mathrm{s}}$ and $C_{\mathrm{e}}$ estimated from the reanalysis data. However, these parameters can be obtained from the auxiliary data that will be delivered with SMOS L1C data in the future.

The conductive heat flux $F_{\mathrm{c}}$ is given by

$F_{\mathrm{c}}=\frac{k_{\mathrm{i}} k_{\mathrm{s}}}{k_{\mathrm{i}} h_{\mathrm{s}}+k_{\mathrm{s}} d_{\mathrm{ice}}}\left(T_{\mathrm{w}}-T_{\mathrm{s}}\right)$,

where $k_{\mathrm{s}}$ and $k_{\mathrm{i}}$ are the thermal conductivities of snow and ice, $T_{\mathrm{w}}$ is the freezing point of sea water, and $T_{\mathrm{S}}$ is the snow surface temperature. In the case of bare ice, $T_{\mathrm{S}}$ is the ice surface temperature. $k_{\mathrm{S}}$ is set to $0.31 \mathrm{~W} \mathrm{~m}^{-1} \mathrm{~K}^{-1}$ according to Yu and Rothrock (1996). The thermal conductivity of ice $k_{\mathrm{i}}$ can be expressed as (Untersteiner, 1964)

$k_{\mathrm{i}}=2.034+0.13 \frac{S_{\text {ice }}}{T_{\text {ice }}-273}$,

where $S_{\text {ice }}$ is in $\mathrm{g} \mathrm{kg}^{-1}$ and $T_{\text {ice }}$ is in K. $T_{\text {ice }}$ can be calculated with

$T_{\text {ice }}=0.5\left(T_{\mathrm{si}}+T_{\mathrm{w}}\right)$,

where $T_{\mathrm{si}}$ is the snow-ice interface temperature calculated with

$T_{\mathrm{si}}=\frac{T_{\mathrm{s}}+\frac{k_{\mathrm{i}} h_{\mathrm{s}}}{k_{\mathrm{s}} d_{\mathrm{ice}}} T_{\mathrm{w}}}{1+\frac{k_{\mathrm{i}} h_{\mathrm{s}}}{k_{\mathrm{s}} d_{\mathrm{ice}}}}$.

To calculate $T_{\mathrm{si}}$ we need to know $k_{\mathrm{i}}$. However, $k_{\mathrm{i}}$ is in turn a function of $T_{\text {ice. }}$. As an approximation, we first calculate $k_{\mathrm{i}}$ with $0.5\left(T_{\mathrm{s}}+T_{\mathrm{w}}\right)$ instead of $0.5\left(T_{\mathrm{si}}+T_{\mathrm{w}}\right)$. Here we ignore the difference between $T_{\mathrm{s}}$ and $T_{\mathrm{si}}$. This makes a minimal change in $k_{\mathrm{i}} . T_{\mathrm{s}}$ is estimated with least-square method for each $d_{\text {ice }}$ under the thermal equilibrium assumption.

\subsection{Retrieval steps}

As discussed in Sect. 3.1, the challenge of using variable $T_{\text {ice }}$ and $S_{\text {ice }}$ in Algorithm II is that both are functions of $d_{\text {ice }}$. The algorithm is based on the forward model consisting of the radiation and thermodynamic models. Therefore, we approximate $d_{\text {ice }}$ by iterating the radiation and the thermodynamic models until a convergence point is found for the solution (Fig. 7). In this process, at each step $T_{\text {ice }}$ and $S_{\text {ice }}$ are calculated for the respective $d_{\text {ice }}$ approximation. The starting point of the iteration is the $d_{\text {ice }}$ retrieved with Algorithm I, which uses a constant $T_{\text {ice }}$ of $-7^{\circ} \mathrm{C}$ and $S_{\text {ice }}$ of $8 \mathrm{~g} \mathrm{~kg}^{-1}$. At each iteration step, we use $d_{\text {ice }}, T_{\text {ice }}$, and $S_{\text {ice }}$ to calculate TB with the radiation model. The calculated TB is then compared with that observed by SMOS. To minimize the difference between the observed and the calculated TBs, the new $d_{\text {ice }}$ is estimated with a linear approximation method. We define two stopping criteria for the iteration, a brightness temperature difference of less than $0.1 \mathrm{~K}$, or an ice thickness difference of less than $1 \mathrm{~cm}$. The first criterion is defined by considering the radiometric accuracy of the brightness temperature measurements and the number of available daily measurements. We apply the first criterion if the ice is thicker than $30 \mathrm{~cm}$ and otherwise we apply the second criterion. We determine $d_{\max }$ with the same criteria for the saturation of TB (the TB change is less than $0.1 \mathrm{~K}$ per $1 \mathrm{~cm} d_{\text {ice }}$ ). We define a saturation factor

$S_{\mathrm{TB}}=d_{\text {ice }} / d_{\max }$.

If the saturation factor reaches $100 \%$, it indicates that $d_{\max }$ can be considered as the minimum ice thickness of the pixel. The SMOS sea ice thickness retrieval does not work well under warm conditions, especially after the onset of melting. 


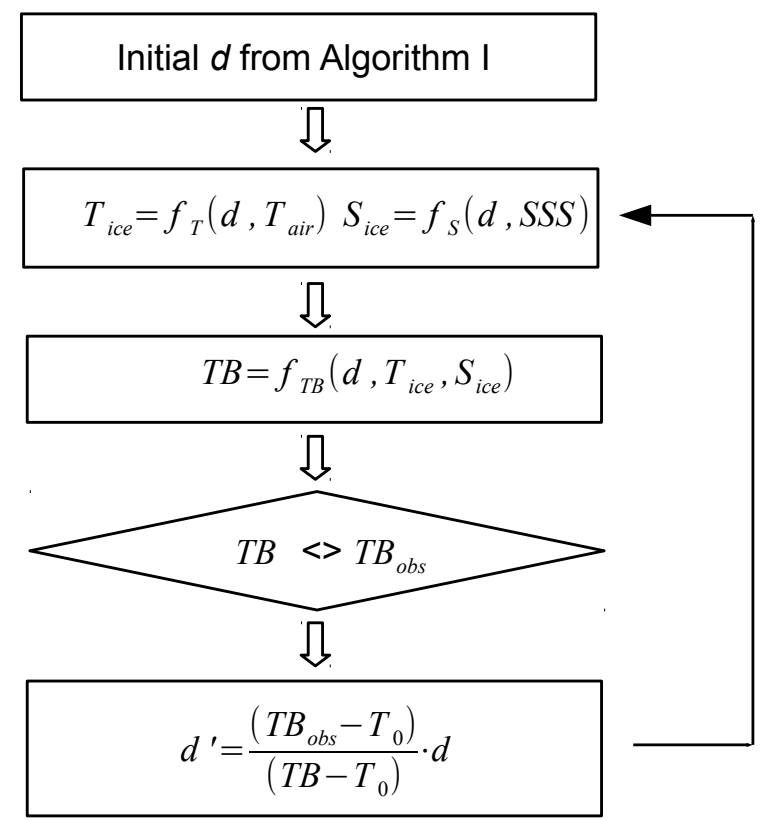

Figure 7. Schematic flow chart of the retrieval steps. $d$ and $d^{\prime}$ are the sea ice thicknesses from the consecutive steps, $\mathrm{TB}$ and $\mathrm{TB}_{\mathrm{obs}}$ are calculated and observed brightness temperatures, and $T_{0}$ is the brightness temperature of sea water assumed to be $100.5 \mathrm{~K}$.

This limitation can be identified if a grid point shows a low $d_{\max }$ and at the same time a high saturation ratio. Both parameters are provided in our data set daily at each grid point.

\section{Assessment of uncertainties}

\subsection{Systematic errors}

In both algorithms we assume $100 \%$ ice coverage for simplicity. TB over ice-sea water mixed areas can be described as

$\mathrm{TB}=\mathrm{TB}_{\text {water }} \times(1-\mathrm{IC})+\mathrm{TB}_{\text {ice }} \times \mathrm{IC}$,

where IC is the ice concentration, $\mathrm{TB}_{\text {water }}$ and $\mathrm{TB}_{\text {ice }}$ are the TBs over sea water and ice, respectively.

SMOS $\mathrm{TB}_{\text {water }}$ shows a stable value of about $100.5 \mathrm{~K}$ with a standard deviation of about $1 \mathrm{~K}$ in the Arctic region. With this constant $\mathrm{TB}_{\text {water }}$, we can calculate $\mathrm{TB}_{\text {ice }}$ using ice concentration charts from passive microwave radiometer data. During the winter, most of the ice covered area in the Arctic has ice concentrations (IC) higher than $90 \%$ (Andersen et al., 2007). The passive microwave radiometer IC charts have an uncertainty of $5 \%$ in the winter time (Andersen et al., 2007). At high concentrations, correcting the retrieved ice thickness with the IC data set with an uncertainty of $5 \%$ can cause higher errors than the $100 \%$ ice coverage assumption. Therefore, we assume $100 \%$ ice coverage in the retrievals. The possible underestimation of ice thickness due to this assump-

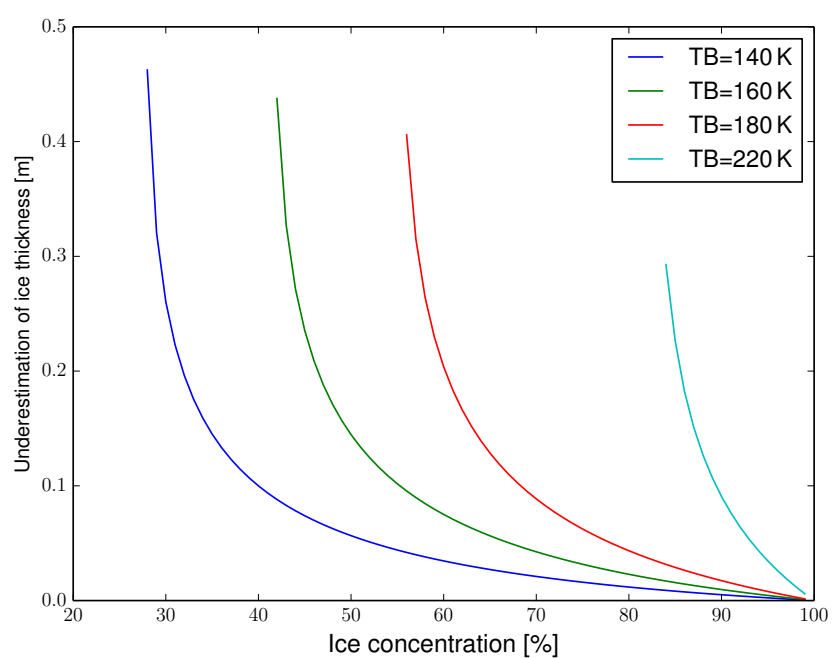

Figure 8. The underestimation of ice thickness caused by the $100 \%$ ice coverage assumption.

tion is investigated with the simple semi-empirical function used in Algorithm I. Figure 8 shows that the bias caused by this assumption increases exponentially with decreasing ice concentration. If we assume a SMOS TB of $220 \mathrm{~K}$, the bias can be very high even for IC of more than $80 \%$. At lower brightness temperatures, the bias caused by this assumption is less than a few centimeters.

\subsection{Sea ice thickness uncertainties}

There are several factors that cause uncertainties in the sea ice thickness retrieval: the uncertainty of the SMOS TB, the uncertainties of the auxiliary data sets, and the assumptions made for the radiation and thermodynamic models.

For our retrieval, we average TB over the incidence angle range of $0-40^{\circ}$. There are usually more than $100 \mathrm{~TB}$ measurements per day at each grid point in the Arctic region. By averaging the measurements, we reduce the measurement uncertainty. We describe the variability of TB by dividing the standard deviation of TB with the square root of the number of measurements during one day at each grid point. The TB variability is usually lower than $0.5 \mathrm{~K}$ in the Arctic, except for the strongly RFI-affected regions. The uncertainties of $T_{\text {ice }}$ and $S_{\text {ice }}$ depend on the uncertainties in $T_{\mathrm{a}}$ and SSS, as well as the uncertainty caused by the missing physics. Both $T_{\mathrm{a}}$ and SSS are derived from model outputs. Due to the sparse observations in the polar regions, $T_{\mathrm{a}}$ and SSS themselves contain large uncertainties.

A first estimation of SMOS-retrieved ice thickness uncertainty is made with Algorithm II based on the std(TB), $\operatorname{std}\left(T_{\text {ice }}\right)$, and $\operatorname{std}\left(S_{\text {ice }}\right)$. The $\operatorname{std}(\mathrm{TB})$ is calculated at each pixel by dividing the standard deviation of all available TB measurements with the sqrt(number of TB measurements) for each day. The $\operatorname{std}\left(S_{\text {ice }}\right)$ is calculated based on the std(SSS) chart (see Fig. 4) and $d_{\text {ice. }}$. The estimation of $\operatorname{std}\left(T_{\text {ice }}\right)$ is rather 
difficult, because it depends not only on $T_{\mathrm{a}}$, but also on the assumptions made in the thermodynamic model. As a first approximation, we assume $1 \mathrm{~K}$ for the $\operatorname{std}\left(T_{\text {ice }}\right)$, which is estimated with the variations in $T_{\mathrm{a}}$. More investigations should be conducted to better estimate the uncertainty in $T_{\text {ice }}$ in the future. The uncertainties provided in the current data set are first estimations. The different error factors are not independent, because they are functions of ice thickness. An elaborate investigation about the correlation between these error factors will be carried out. At present, each error caused by the standard deviations of brightness temperature, ice salinity, and ice temperature is estimated by keeping the other parameters constant. The total uncertainty given in the data set is the sum of these errors. Errors caused by the assumptions about fluxes and snow thickness have not yet been included. We consider this as future work.

In Table 1, we show an example of estimated ice thickness uncertainties for conditions where $T_{\text {ice }}$ varies from $-10^{\circ} \mathrm{C}$ to $-2^{\circ} \mathrm{C}$, and $S_{\text {ice }}$ varies from $2 \mathrm{~g} \mathrm{~kg}^{-1}$ to $8 \mathrm{~g} \mathrm{~kg}^{-1}$. We assume a standard deviation of $0.5 \mathrm{~K}, 1 \mathrm{~K}$, and $1 \mathrm{~g} \mathrm{~kg}^{-1}$ for TB, $T_{\text {ice }}$, and $S_{\text {ice }}$, respectively. The ice thickness uncertainty caused by $\operatorname{std}(\mathrm{TB})$ is rather small for thin ice less than $50 \mathrm{~cm}$, and increases exponentially for thicker ice. The uncertainty caused by $\operatorname{std}\left(T_{\text {ice }}\right)$ is higher than that caused by $\operatorname{std}(\mathrm{TB})$, with an increasing trend with increasing ice thickness. The uncertainty of $S_{\text {ice }}$ has little impact on the ice thickness retrieval for saline ice with $S_{\text {ice }}$ of more than $5 \mathrm{~g} \mathrm{~kg}^{-1}$. However, for less saline ice, which is typical in regions with river run-off, $\operatorname{std}\left(S_{\text {ice }}\right)$ has much more impact on the ice thickness uncertainty than the other two parameters when $d_{\text {ice }}$ is less than half a meter.

\section{The effect of the subpixel-scale heterogeneity on the thickness retrieval (Algorithm II* post-processing)}

The limitations of SMOS measurements are twofold: (1) SMOS has a large spatial resolution (about $35 \mathrm{~km}$ at nadir view), and thus the SMOS signal comes from diverse ice types and even open water, within the resolution. It is difficult to decide what kind of ice thickness SMOS really measures, since the ice thickness distribution within the spatial resolution is not well known. (2) Under cold Arctic conditions, the maximum retrievable ice thickness from SMOS is about $50 \mathrm{~cm}$, and varies depending on the ice temperature and ice salinity. SMOS-derived ice thickness depends on the thin ice part of the ice thickness distribution within the spatial resolution, while the contribution of the thicker ice part cannot be quantified due to the limited penetration depth. Thus, the overall mean thickness for a mixture of thin and thick ice can only be estimated in a statistical sense if the thickness distribution function is known.

Sea ice deformation patterns are often described using self-similar functions, such as the lognormal distribution (Erlingsson, 1988; Key and McLaren, 1991; Tan et al., 2012). A theory of sea ice thickness distribution was developed by
Thorndike et al. (1975). Models that include ice growth and deformation may be used to simulate the evolution of the thickness distribution (Thorndike, 1992; Godlovitch et al., 2012). A common feature of simulations and empirical observations is the exponential tail resulting from dynamic deformation processes. The dominant effect of the thin ice part on the SMOS-derived ice thickness leads to a considerable underestimation of sea ice thickness if the retrieval model is based on a plane sea ice layer. In the following, we use airborne sea ice thickness measurements in order to parameterize the thickness distribution function and to investigate the effect of the subpixel-scale heterogeneity on the thickness retrieval.

NASA's Operation IceBridge (OIB) airborne campaigns obtained large scale profiles of sea ice thickness derived from a laser altimeter system (Kurtz et al., 2013). The footprint size of a single laser beam is about $1 \mathrm{~m}$, and the vertical accuracy is given as $6.6 \mathrm{~cm}$. The sea ice thickness is estimated from the freeboard by accounting for the snow thickness and by making assumptions about the densities of ice and snow. Simultaneously, the snow thickness is retrieved using a snowdepth radar. Here, we use the OIB "quicklook" data as obtained from the NSIDC website.

We assume that the sea ice thickness follows a lognormal distribution:

$p\left(d_{\text {ice }}, \mu, \sigma\right)=\frac{1}{d_{\text {ice }} \sigma \sqrt{2 \pi}} e^{-\frac{\left(\log \left(d_{\text {ice }}\right)-\mu\right)^{2}}{\left(2 \sigma^{2}\right)}}$,

with the two parameters $\operatorname{logmean} \mu$ and logsigma $\sigma$. Furthermore, we assume a constant logsigma value $\sigma$ to approximate the thickness distribution function with only one independent variable. To test this assumption, we split the 2012 and 2013 OIB Arctic sea ice thickness data into segments of about $30 \mathrm{~km}$ length. We found that using constant values $\sigma=0.6 \pm 0.1$ rejects less than $15 \%$ of the segments tested with the Kolmogorov-Smirnov statistics at a significance level of $95 \%$. The parameter $\sigma$ increases with increasing segment length and converges to about 0.7 for the maximal number of samples. The parameter $\sigma$ changed only slightly from 0.692 to 0.695 , while the mean thickness decreased considerably from $3.1 \mathrm{~m}$ to $2.2 \mathrm{~m}$ when considering the entire data sets of the years 2012 and 2013, respectively (Fig. 9). One percent of the 2012 thickness data $\left(N_{1 \%}=3430\right)$ are above $10 \mathrm{~m}$, and one per mill exceeds $16 \mathrm{~m}$ with a maximum thickness value as large as $27.4 \mathrm{~m}$, which justifies the exponential tail of the distribution function. Under the assumption of a lognormal ice thickness distribution, the logmean $\mu$ is calculated using a least-square method comparing with the observed brightness temperature at each grid point. The effect of the ice thickness distribution on TB is taken into account by the integration over the thickness range according to the 
Table 1. Estimated ice thickness uncertainties caused by $\operatorname{std}(\mathrm{TB}), \operatorname{std}\left(T_{\text {ice }}\right)$, and $\operatorname{std}\left(S_{\text {ice }}\right)$.

\begin{tabular}{llll}
\hline$d_{\text {ice }}$ & $\operatorname{std}(\mathrm{TB})=0.5 \mathrm{~K}$ & $\operatorname{std}\left(T_{\text {ice }}\right)=1 \mathrm{~K}$ & $\operatorname{std}\left(S_{\text {ice }}\right)=1 \mathrm{~g} \mathrm{~kg}^{-1}$ \\
\hline $0-10 \mathrm{~cm}$ & less than $1 \mathrm{~cm}$ & less than $1 \mathrm{~cm}$ & less than $1 \mathrm{~cm}$ \\
$10-30 \mathrm{~cm}$ & less than $1 \mathrm{~cm}$ & $1-5 \mathrm{~cm}$ & $1-13 \mathrm{~cm}$ \\
$30-50 \mathrm{~cm}$ & $1-4 \mathrm{~cm}$ & $2-10 \mathrm{~cm}$ & $2-22 \mathrm{~cm}$ \\
more than $50 \mathrm{~cm}$ & $4 \mathrm{~cm}-$ more than $1 \mathrm{~m}$ & $7 \mathrm{~cm}-$ more than $1 \mathrm{~m}$ & up to $40 \mathrm{~cm}$ \\
\hline
\end{tabular}

superposition principle:

$\mathrm{TB}^{*}\left(d_{\text {ice }}\right)=\int_{0}^{\max \left(d_{\text {ice }}\right)} \operatorname{TB}\left(d_{\text {ice }}\right) g\left(d_{\text {ice }}\right) d d_{\text {ice }}$,

with the thickness distribution function $g\left(d_{\text {ice }}\right)$ and the brightness temperature of a single/plane-layer model $\mathrm{TB}\left(d_{\text {ice }}\right)$. While $d_{\max }$ is the maximum retrievable singlelayer ice thickness, $\max \left(d_{\text {ice }}\right)$ is the maximum of ice thickness in the ice thickness distribution function. The brightness temperature weighted with the thickness distribution TB* suggests a sensitivity to ice thicknesses larger than $d_{\max }$. Here, $d_{\max }$ and $d_{\text {ice }}$ both refer to the single-layer thickness. The real mean thickness, denoted as $H$, is strongly underestimated if the retrieval does not account for the thickness distribution. The overall effect can be explained as an apparently deeper penetration depth, caused by the leading edge of the thickness distribution. The implementation of a radiative transfer model that includes this effect is straightforward, but computationally expensive because of the integration. A post-processing look-up table for the single-layer model has been generated to estimate an approximate correction factor. This method that converts the single-layer thickness $d_{\text {ice }}$ to the mean thickness $H$ is called Algorithm II* hereinafter. Figure 10 shows that the involved correction factor increases with increasing salinity and decreasing temperature.

By implementing a lognormal function in Algorithm II*, which is an approximation of the ice thickness distribution within the SMOS spatial resolution, we try to correct the underestimation of ice thickness caused by the plane ice layer assumption in Algorithm II. However, there are uncertainties concerning the ice thickness distribution function and the determination of logsigma, which was derived from IceBridge data, mainly over multi-year ice regions. The validity of this lognormal function in thin ice areas remains to be investigated. Under the assumption that the ice thicknesses within SMOS spatial resolution follow a lognormal distribution, the SMOS ice thickness retrieved from Algorithm II approximates the modal ice thickness of the lognormal distribution, and the ice thickness retrieved from Algorithm II* approximates the mean ice thickness.
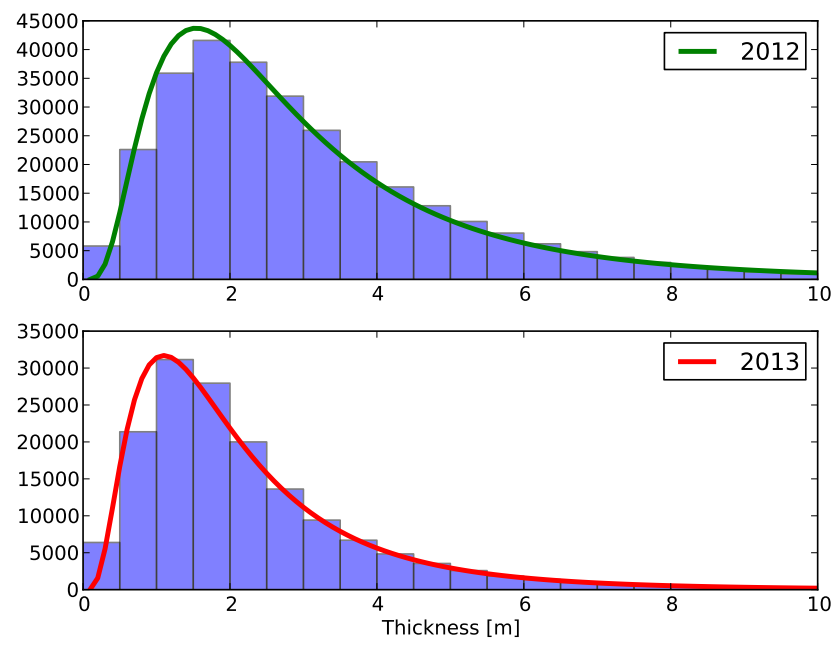

Figure 9. Sea ice thickness distribution derived from NASA's Operation IceBridge data from 2012 (upper panel, $\sigma=0.692$ ) and 2013 (lower panel, $\sigma=0.695$ ). The $y$ axis is the number of occurrence.

\section{Comparison of ice thicknesses retrieved with Algorithms I, II, and II*}

In this section, we analyze the time series of ice thicknesses retrieved from Algorithm I, II, and II* at single grid points in the Laptev Sea and the Beaufort Sea (Point 1: $77.5^{\circ} \mathrm{N}$, $137.5^{\circ} \mathrm{E}$, Point 2: $71.0^{\circ} \mathrm{N}, 165.0^{\circ} \mathrm{W}$, Point $3: 74.5^{\circ} \mathrm{N}$, $\left.127.0^{\circ} \mathrm{E}\right)$. The time series begin on 15 October 2011. The time series of ice thickness extracted from two different sea ice assimilation systems are included for comparison. In addition, we show time series of SMOS TB together with ice concentration and derived snow/ice surface temperature.

One of the assimilation systems is the TOPAZ system. TOPAZ is an advanced data assimilation system, using the HYbrid Coordinate Ocean Model (HYCOM) and ElasticViscous-Plastic (EVP) ice rheology (Bertino and Lisæter, 2008). TOPAZ has a resolution between 18 and $36 \mathrm{~km}$ with 22 isopycnal layers. The assimilated observations are satellite-observed Sea Level Anomaly (SLA), Sea Surface Temperature (SST), sea ice concentrations from AMSR-E, sea ice drift products from Laboratory of Oceanography From Space (CERSAT), and Coriolis in situ temperature and salinity profiles. The TOPAZ system has been in operation since 1 January 2003. The major outcomes in terms of products are weekly issued short term forecasts. 


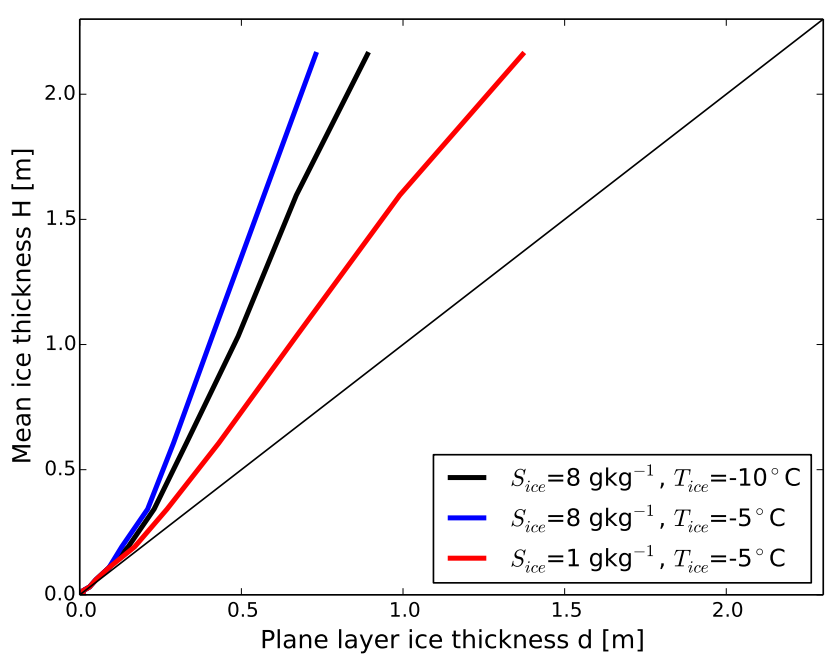

Figure 10. Relationship between the plane ice layer thickness $d_{\text {ice }}$ and the mean inhomogeneous ice layer thickness $H$ at different $T_{\text {ice }}$ and $S_{\text {ice. }}$ The thin black line is the 1.1 unity line.

The other assimilation system is the Pan-Arctic Ice Ocean Modeling and Assimilation System (PIOMAS) (Zhang and Rothrock, 2003). It is based on a coupled ocean-ice model forced with National Centers for Environmental Prediction Atmospheric Reanalysis data. PIOMAS assimilates satelliteobserved sea ice concentration and sea surface temperature data.

At Point 1, which is located in the northern Laptev Sea, Algorithm I and II show very similar $d_{\text {ice }}$, ranging from $0 \mathrm{~m}$ to about $0.3 \mathrm{~m}$ (Fig. 11) for the first 30 days. The TB increases from about $100 \mathrm{~K}$ to about $230 \mathrm{~K}$. In this TB range, $d_{\text {ice }}$ is the dominant factor of TB variation (Kaleschke et al., 2012). In the next 30 days, TB increases to about $240 \mathrm{~K}$, whereas $d_{\text {ice }}$ increases from about $0.3 \mathrm{~m}$ to about $0.4 \mathrm{~m}$ in Algorithm I and to more than $0.5 \mathrm{~m}$ in Algorithm II. From mid-December to the end of April, TB shows little variability with a mean value of $237.4 \mathrm{~K}$ and a standard deviation of $1.9 \mathrm{~K}$. In this period, $d_{\text {ice }}$ from Algorithm I shows a stable value around $0.35 \mathrm{~m}$ with a standard deviation of $3 \mathrm{~cm}$, which results from the constant parameters assumed in Algorithm I. In contrast, $d_{\text {ice }}$ from Algorithm II shows an average value of $0.48 \mathrm{~m}$ with a standard deviation of $11 \mathrm{~cm}$. The strong variability in $d_{\text {ice }}$ is mainly caused by $T_{\text {ice }}$. A correlation coefficient $R$ of -0.7 can be found between $T_{\text {ice }}$ and $d_{\text {ice }}$. In the total time period of 200 days, $d_{\text {ice }}$ from Algorithm II is on average $10 \mathrm{~cm}$ thicker than that from Algorithm I. The ice thickness corrected with the thickness distribution function (Algorithm II*) is about two times that of Algorithm II.

Simulated ice thicknesses from TOPAZ and PIOMAS show continuous ice growth during the time period, however, with more than $0.5 \mathrm{~m}$ span between them (shaded area in the upper panel of Fig. 11). The ice thicknesses retrieved with Algorithm II* correspond well with those from TOPAZ and
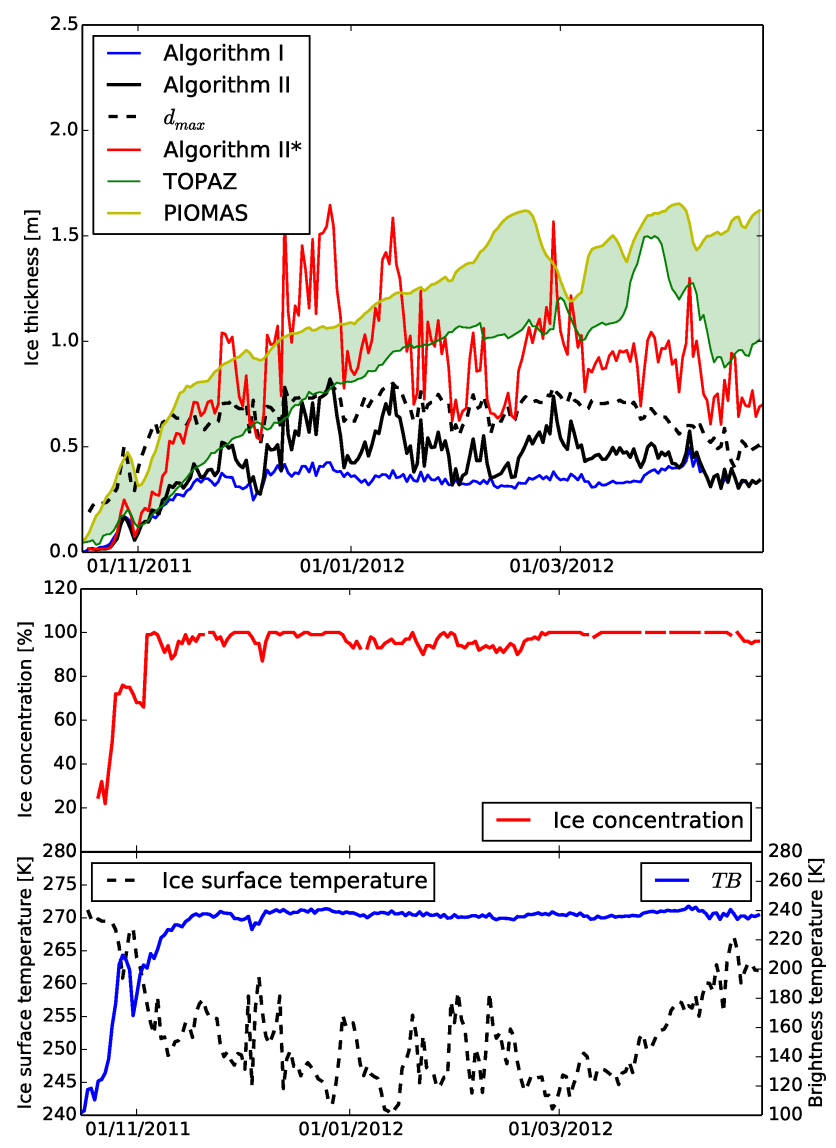

Figure 11. Time series of ice thickness derived from Algorithm I, II, and II*, together with $d_{\max }$ and simulated ice thicknesses from TOPAZ and PIOMAS (upper panel) and time series of ice concentration (middle panel), snow (or ice in the case of bare ice) surface temperature and SMOS TB (lower panel) at Point $1\left(77.5^{\circ} \mathrm{N}\right.$, $\left.137.5^{\circ} \mathrm{E}\right)$

PIOMAS in the first three months. However, from March to April TOPAZ and PIOMAS show further growth in the ice thickness, whereas SMOS shows rather constant or decreasing trends. The decreasing trend in $d_{\text {ice }}$ corresponds to the decreasing $d_{\max }$ caused by the increasing $T_{\mathrm{s}}$.

Point 2 is located in the Beaufort Sea, near Barrow. The first sea ice occurrence happens in mid-November, one month later than at Point 1 . A few days after the first occurrence of sea ice, the ice concentration rapidly reaches nearly $100 \%$ (Fig. 12). In the following 80 days, $T_{\mathrm{s}}$ decreases from about $270 \mathrm{~K}$ to $240 \mathrm{~K}$, and $d_{\text {ice }}$ retrieved with Algorithm II* increases from a few centimeters to more than $1.5 \mathrm{~m}$. In this period, the ice thickness growth from SMOS Algorithm II* agrees well with that simulated by TOPAZ and PIOMAS. Just as at point 1 , after the three month freeze-up period, the SMOS-retrieved $d_{\text {ice }}$ reaches its maximum with a decreasing trend in April, which corresponds to the increasing $T_{\mathrm{s}}$.

Point 3 is located north of the Lena delta, where frequent formation of polynyas can be observed. The area 

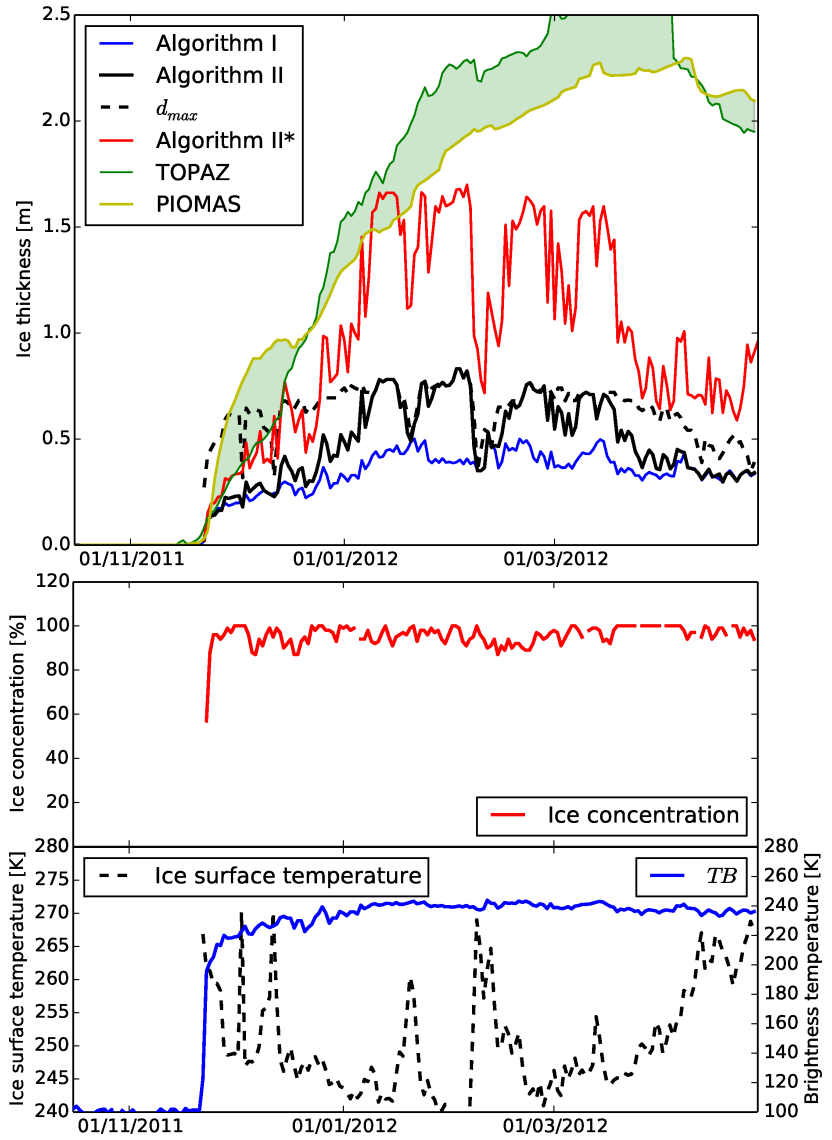

Figure 12. Time series of ice thicknesses derived from Algorithm I, II, and II*, together with $d_{\max }$ and simulated ice thicknesses from TOPAZ and PIOMAS (upper panel) and time series of ice concentration (middle panel), snow (or ice in the case of bare ice) surface temperature and SMOS TB (lower panel) at Point $2\left(71.0^{\circ} \mathrm{N}\right.$, $\left.165.0^{\circ} \mathrm{W}\right)$

is characterized by large interannual variations, the consequence of an enormous freshwater input from the Lena river, and by ice formation and salt rejection processes taking place in polynyas offshore of the fast ice edge. Anticyclonic wind conditions force the riverine water northwards and result in a stronger density stratification in the eastern Laptev sea during winter. Cyclonic atmospheric circulation deflects the freshwater plume of the Lena river eastward towards the East Siberian Sea, thus causing higher salinity in the eastern Laptev Sea and the area around the West New Siberian (WNS) polynya.

The strong variability of ice thicknesses in SMOS and in the model outputs shows good correlation (Fig. 13). The decrease and increase of ice thicknesses in SMOS and in the model outputs are very likely caused by the drift of thick ice due to wind forcing and thin ice formation in the polynya areas. From March to April, there is a large discrepancy between the model outputs and the SMOS-derived ice thickness. While model outputs show an ice thickness of more
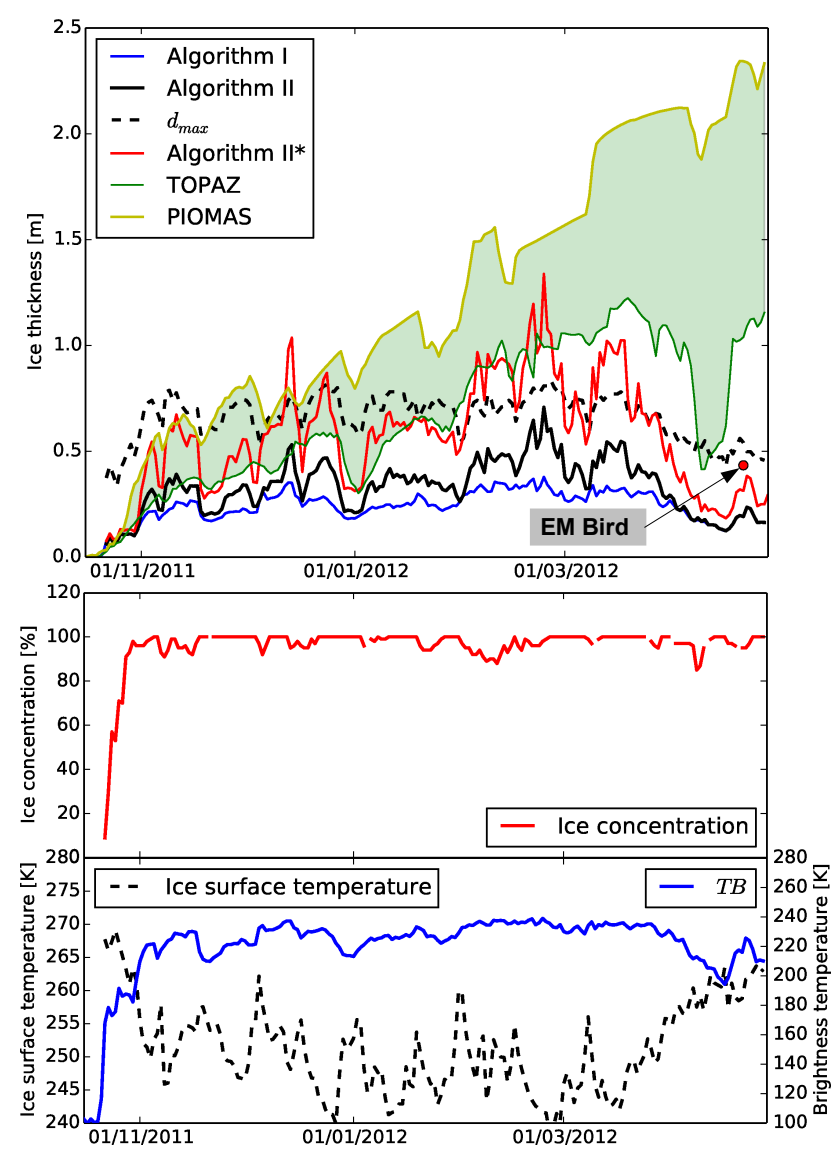

Figure 13. Time series of ice thicknesses derived from Algorithm I, II, and II*, together with $d_{\max }$ and simulated ice thicknesses from TOPAZ and PIOMAS (upper panel) and time series of ice concentration (middle panel), snow (or ice in the case of bare ice) surface temperature and SMOS TB (lower panel) at Point $3\left(74.5^{\circ} \mathrm{N}\right.$, $\left.127.0^{\circ} \mathrm{E}\right)$.

than $2 \mathrm{~m}$ in April, SMOS-derived ice thickness is less than half a meter.

Sea ice thickness measurements were carried out in this area during helicopter-borne ice thickness surveys performed in the Laptev Sea during the Transdrift (TD) XX campaign in April 2012 (Kaleschke et al., 2013). The helicopter-borne ice thickness measurements were made with an electromagnetic (EM)-Bird. EM-Bird consists of a laser altimeter and an assembly of coils that transmit and receive low-frequency EM fields. Utilizing the contrast of electrical conductivity between sea water and ice, EM-Bird can determine the distance to the ice-water interface (Haas et al., 2009). The laser altimeter yields the distance to the uppermost reflecting surface. Hence, the obtained ice thickness is the ice plus snow thickness from the difference between the laser range and the EM-derived distance. The accuracy over level sea ice is on the order of $10 \mathrm{~cm}$ (Pfaffling et al., 2007). Uncertainties in the ice thickness measurements may arise from the assumption that sea ice is a non-conductive medium. Over thin ice, 
this assumption may be invalid because the conductivity of saline young ice can be significantly higher than that of older first-year or multi-year ice. This can lead to an underestimation of ice thickness.

The survey flight made on 20 April has a length of about $200 \mathrm{~km}$ and covers mostly thin ice formed in the WNS polynya and the Anabar-Lena polynya. A period of strong and consistent offshore winds led to the development of an extensive thin ice zone extending several hundred kilometers offshore. Point 3 is located in the middle of the flight track. Therefore, we use the EM-Bird measurements to validate the SMOS-derived ice thickness. During the flights, the EM-Bird recorded a total of 46386 measurements with a mean value of $43 \mathrm{~cm}$ and a standard deviation of $33 \mathrm{~cm}$. This agrees well with the $31 \mathrm{~cm}$ ice thickness from SMOS Algorithm II*, considering that the EM-Bird-derived ice thickness is the sum of the thicknesses of the ice layer and the overlying snow. The SMOS ice thickness along the $200 \mathrm{~km}$ flight track is quite homogeneous, with a standard deviation of $1 \mathrm{~cm}$. The comparison shows that in the polynya area, SMOS estimates the ice thickness better than TOPAZ or PIOMAS.

After the time series comparison at single points, we compare the daily ice thickness distribution from the three algorithms in the Arctic on 1 February 2013. As can be seen in Fig. 14 the mean ice thickness considerably increases from Algorithm I to Algorithm II*. In the central Arctic, which is covered with thick multi-year ice, TB reaches its saturation. Therefore, none of the algorithms can deliver reliable ice thickness information in the thick multi-year ice area. If we consider only the pixels where TB has not reached its saturation, ice thickness from Algorithm II* is on average $0.82 \mathrm{~m}$, which is about $40 \mathrm{~cm}$ thicker than that from Algorithm II and $55 \mathrm{~cm}$ thicker than that from Algorithm I. However, the increase of ice thickness varies from region to region, depending on SSS and weather conditions. For example, in the Laptev Sea, where the SSS is much lower than that in the central Arctic, the difference between Algorithm II and Algorithm I is as large as half a meter. In contrast, in parts of the Kara Sea and the northern Barents Sea, little change can be observed between Algorithm I and II. The increase of ice thickness in Algorithm II compared to Algorithm I is caused by the deviation of estimated $T_{\text {ice }}$ and $S_{\text {ice }}$ from the constant values assumed in Algorithm I. To investigate the contribution of $T_{\text {ice }}$ and $S_{\text {ice }}$ in the thickness retrieval separately, we carried out two tests with the data from 1 February 2013. In the first test, $S_{\text {ice }}$ is assumed to be $8 \mathrm{~g} \mathrm{~kg}^{-1}$ as in Algorithm I and we vary only $T_{\text {ice. }}$. In the second test, $T_{\text {ice }}$ is assumed to be $-7^{\circ} \mathrm{C}$ as in Algorithm I and $S_{\text {ice }}$ is calculated from SSS. In both tests, we assume a plane ice layer. If we only consider the pixels where TB has not reached its saturation, the change of ice thickness caused by $T_{\text {ice }}$ in Test 1 varies from $-10 \mathrm{~cm}$ to more than $50 \mathrm{~cm}$, with an average of $11 \mathrm{~cm}$. Larger changes are found where cold air temperatures prevail. The ice thickness change caused by $S_{\text {ice }}$ from Test 2 is on aver-

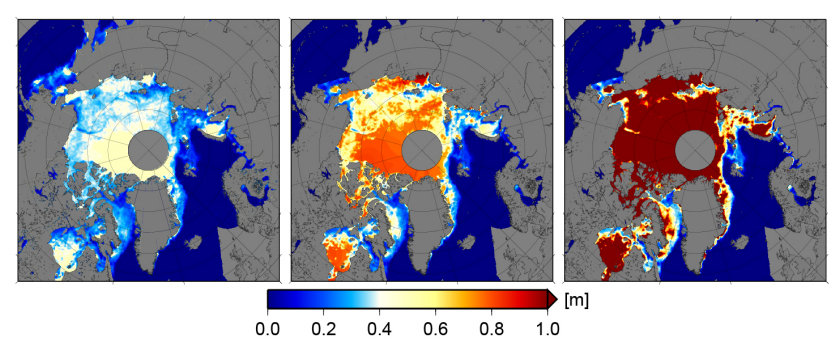

Figure 14. SMOS ice thickness derived from retrieval algorithm I, II, and II* in the Arctic on 1 February 2013.

age $3 \mathrm{~cm}$. However, differences up to $20 \mathrm{~cm}$ and $60 \mathrm{~cm}$ can be found in the Laptev Sea and in the Baltic Sea.

SMOS-retrieved ice thickness represents both thermodynamic and dynamic evolution of an ice layer, with a spatial resolution of about $35 \mathrm{~km}$ on a daily basis in the polar regions. The variability of SMOS-retrieved ice thickness comes partly from ice drift and ice concentration variation, partly from the changing surface air temperature. We compared SMOS ice thickness with PIOMAS and TOPAZ model outputs just to see whether the magnitude of the ice thicknesses are on the same order. The correlation between SMOS ice thickness and model outputs is low if we remove the seasonal cycle. The advantage of the SMOS ice thickness product is that it can reflect, to some extent, the fine scales of temporal and spatial variability of thin ice thickness, which most ocean-sea ice coupled models are not able to simulate. Ice thicknesses derived from a thermodynamic model or from a simple freezing-degree-day ice growth calculation cannot reflect the variations caused by the ice dynamics which could, however, be captured by SMOS.

The comparison between Algorithm I and II shows that by taking into account the variability of ice temperature and ice salinity, the Arctic-wide ice thickness distribution becomes more realistic. However, the underestimation of ice thickness caused by the one plane layer assumption is still a shortcoming of Algorithm II. This problem is partly solved in Algorithm II* by implementing a lognormal ice thickness distribution function, which is a first approximation of the inhomogeneity of natural ice. The inter-comparison with model outputs shows a considerable advantage of Algorithm II*, which produces ice thickness values close to the model outputs, at least in the freeze-up period. Furthermore, good agreement is found between Algorithm II* and EM-Bird validation data in the Laptev Sea. Therefore, Algorithm II* is used to retrieve ice thickness from SMOS data operationally.

\section{Ice thickness growth and distribution as seen by SMOS during the freeze-up period}

SMOS-derived ice thickness shows continuous growth and expansion of first year ice in the Arctic during the freeze-up period. Figure 15 shows the monthly mean sea ice thickness 

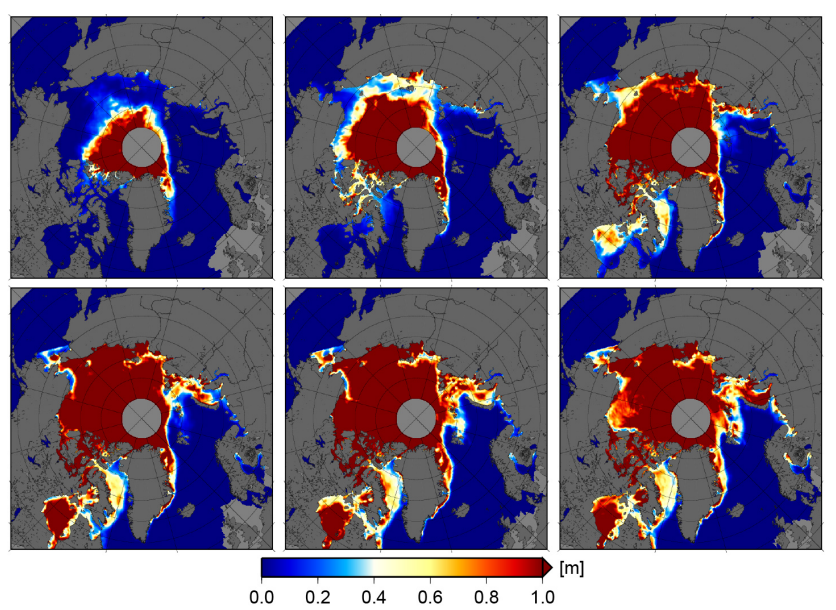

Figure 15. Monthly sea ice thickness derived from Algorithm II* during the freeze-up period of October 2012 to March 2013 (from upper left to lower right) in the Arctic. Months: October 2012 (upper left), November 2012 (upper middle), December 2012 (upper right), January 2013 (lower left), February 2013 (lower middle), and March 2013 (lower right).

from October 2012 to March 2013 retrieved with Algorithm II*. From October to November, thin first-year ice extends to most areas of the East Siberian Sea, the Laptev Sea, and the Beaufort Sea. In addition to the area expansion, an increase of ice thickness due to the thermodynamic growth can also be observed. In December, first-year ice reaches a thickness of more than $1 \mathrm{~m}$ in the Laptev Sea and the Beaufort Sea. In March 2013, large areas of thin ice with a thickness less than $40 \mathrm{~cm}$ are observed in the Beaufort Sea, which is caused by the opening of leads and polynyas in this period.

\section{Comparison of SMOS and MODIS ice thickness charts in the Kara Sea}

\subsection{Sea ice thickness derived from MODIS data}

For the initial verification of SMOS-retrieved sea ice thickness, we use MODIS ice thickness charts for the Kara Sea. The validation extends over an area of $1500 \mathrm{~km}$ by $1350 \mathrm{~km}$. The area is suitable for SMOS ice thickness validation because even in the winter time it is frequently covered by thin first-year ice, which SMOS can best detect. To compare SMOS and MODIS ice thicknesses, we reduce the $1 \mathrm{~km}$ spatial resolution of the MODIS thickness charts to the SMOS ice thickness grid resolution of $12.5 \mathrm{~km}$ by spatial averaging.

We first compare ice thickness distributions from SMOS and MODIS for two selected days (26 December 2010 and 2 February 2011), on which a sufficient amount of pixels with valid MODIS data is available. After that we collect all pixels with valid MODIS data from 30 days during the two winter seasons 2009-2010 and 2010-2011 and carry out a pixel-to-pixel comparison. The 30 days are selected man- ually. MODIS ice charts with strong cloud limitation are excluded. We use SMOS Algorithm II for the comparison with ice thicknesses derived from MODIS thermal measurements because both represent the modal (level) ice thickness of undeformed ice.

\subsection{Daily comparison}

Figure 16 shows the modal MODIS ice thickness in a $12.5 \mathrm{~km}$ grid resolution, the SMOS ice thicknesses retrieved from Algorithm I and II, and the histogram of the three ice thickness data sets in the Kara Sea on 26 December 2010. Ice concentration from the same day (Fig. 17) shows near $100 \%$ ice coverage in the ice-covered area except for the marginal ice zone. Here we use the ice concentration maps derived from SSM/I with the ARTIST Sea Ice (ASI) algorithm. Both SMOS and MODIS show similar patterns of thin and thick ice distributions, whereas SMOS ice thickness from Algorithm I is considerably lower than the other two in the thicker ice range. Surface air temperature $T_{\mathrm{a}}$ over the ice covered area varies from -30 to $-20^{\circ} \mathrm{C}$ (Fig. 17), providing favorable conditions for both SMOS and MODIS ice thickness retrievals (Kaleschke et al., 2010; Yu and Rothrock, 1996).

The insulation effect of snow is considered in the SMOS Algorithm II and in the MODIS ice thickness retrieval, but not in the SMOS Algorithm I. In Algorithm II $T_{\mathrm{s}}$ and $d_{\text {ice }}$ are retrieved simultaneously with $T_{\mathrm{a}}$ as a boundary condition. The SMOS-derived $T_{\mathrm{S}}$ is in good agreement with that from MODIS (Hall et al., 2004) (Fig. 17). The mean $T_{\mathrm{s}}$ from MODIS and SMOS are both $247 \mathrm{~K}$, and the root mean square deviation (RMSD) is $4 \mathrm{~K}$. Discrepancies can be seen in the marginal ice zone and in the Ob estuary, where the low salinities are not well represented by the ocean model. In the marginal ice zone with lower ice concentrations, SMOS strongly underestimates ice thickness, which leads to toowarm $T_{\mathrm{s}}$. In SMOS Algorithm II $T_{\mathrm{s}}$ is used to calculate the bulk ice temperature, which is a variable parameter in the radiation model to calculate the emissivity of an ice layer.

In total, there are 4167 pixels in $12.5 \mathrm{~km}$ grids with valid MODIS ice thicknesses. For these pixels, MODIS has a mean thickness of $44 \mathrm{~cm}$, whereas SMOS has an average of $32 \mathrm{~cm}$ and $47 \mathrm{~cm}$ from Algorithm I and II, respectively. The correlation coefficient $R$ and RMSD between the SMOS Algorithm II and MODIS are 0.60 and $20 \mathrm{~cm}$, whereas for SMOS Algorithm I and MODIS they are 0.57 and $23 \mathrm{~cm}$, respectively. If we only consider the 2679 pixels with a MODIS ice thickness less than $50 \mathrm{~cm}$, then the mean ice thicknesses of SMOS Algorithm I, SMOS Algorithm II and MODIS are $29 \mathrm{~cm}$, $40 \mathrm{~cm}$, and $29 \mathrm{~cm}$, respectively. This means, in the thin ice range, Algorithm II overestimates ice thickness compared to MODIS. $T_{\text {ice }}$ derived from $T_{\mathrm{s}}$ in Algorithm II is on average $263.6 \mathrm{~K}$, which is $2.5 \mathrm{~K}$ lower than that assumed in SMOS Algorithm I. This can partly explain the ice thickness difference between Algorithm I and II. The SMOS-derived ice 


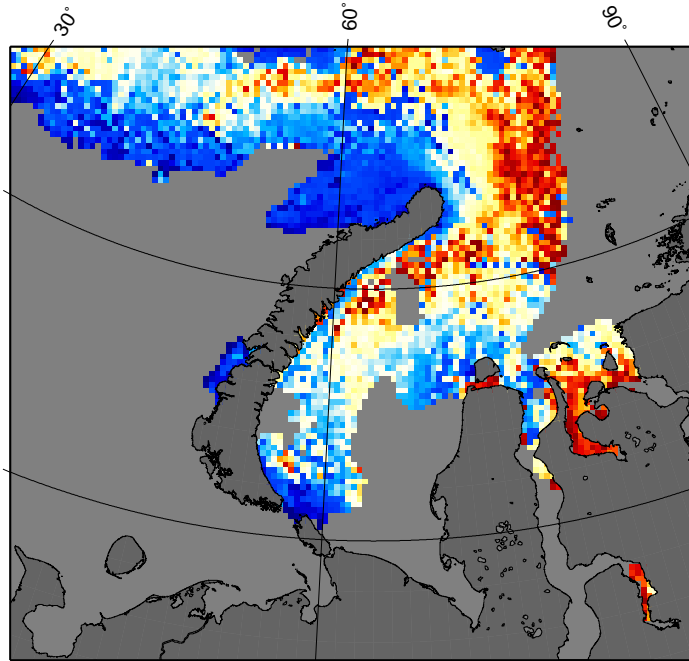

20101226 Sea ice thickness MODIS ஓं

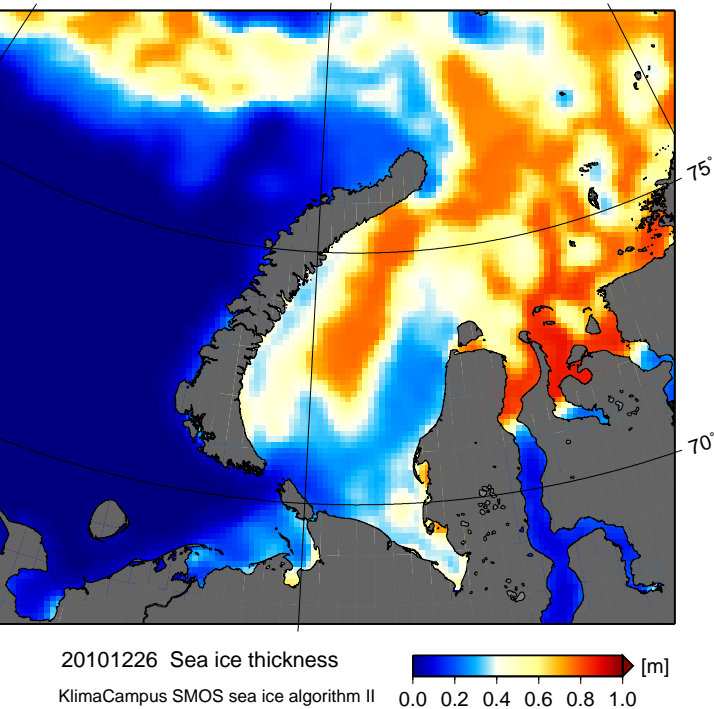

अं 8.

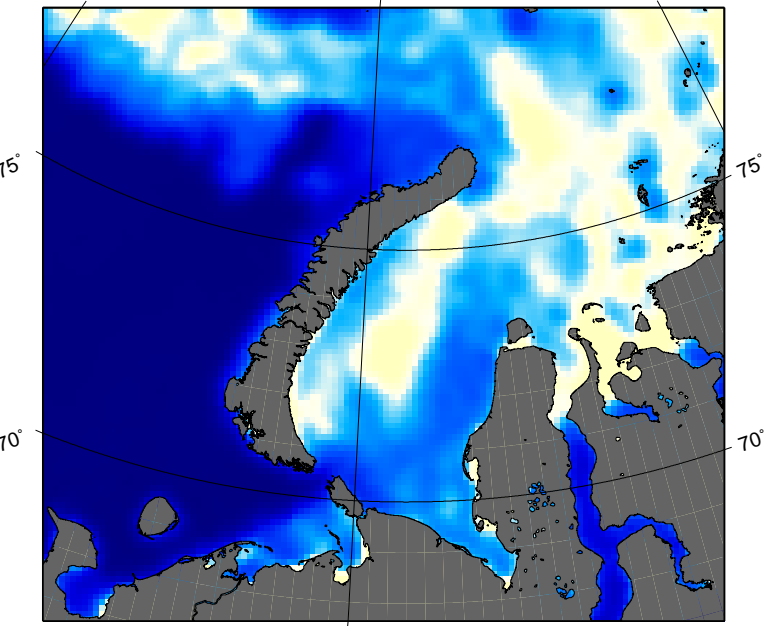

20101226 Sea ice thickness

KlimaCampus SMOS sea ice algorithm I

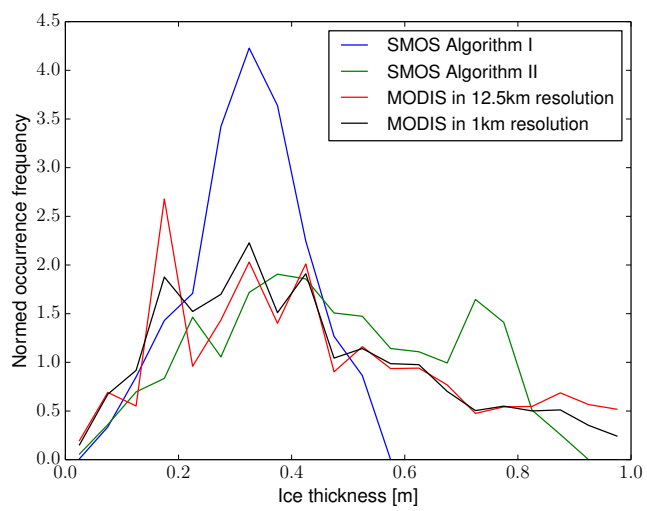

Figure 16. The modal MODIS ice thickness with $12.5 \mathrm{~km}$ grid resolution (upper left), SMOS ice thicknesses retrieved from Algorithm I (upper right) and II (lower left), and the histogram of the three ice thickness data (lower right) in the Kara Sea on 26 December 2010.

thickness decreases with increasing $T_{\text {ice }}$ under cold conditions (Maaß, 2013a).

Similar results can be derived from another comparison on 2 February 2011 (see Figs. 18 and 19). On this day, large areas of thin ice can be observed from SMOS and MODIS near the Kara Strait and in the estuaries. In both regions polynyas appear frequently due to the strong wind forcing. Under cold air temperatures, the polynyas are soon covered by thin ice. Both SMOS and MODIS show ice thicknesses in the range of $20-40 \mathrm{~cm}$ in the polynyas with similar distribution patterns. Ice concentration is normally higher than $90 \%$ except for the marginal ice zone. As on 26 December 2010, surface air temperature over the Kara Sea is as low as $-30^{\circ} \mathrm{C}$. In total 4016 pixels have valid MODIS data. The mean ice thickness of
SMOS Algorithm I, SMOS Algorithm II, and MODIS for the pixels are $33 \mathrm{~cm}, 50 \mathrm{~cm}$, and $47 \mathrm{~cm}$, respectively. The correlation coefficient and RMSD between the SMOS Algorithm II and MODIS are 0.61 and $21 \mathrm{~cm}$, whereas between SMOS Algorithm I and MODIS they are 0.59 and $26 \mathrm{~cm}$, respectively. The mean surface temperatures from MODIS and SMOS are $246 \mathrm{~K}$ and $245 \mathrm{~K}$, with a RMSD of $4 \mathrm{~K}$.

\subsection{Comparison with 30 days data from the two winter seasons}

In total, 33 and 87 days of MODIS validation data are available for the winter seasons of 2009-2010 and 2010-2011, respectively. However, many of them have only small areas 

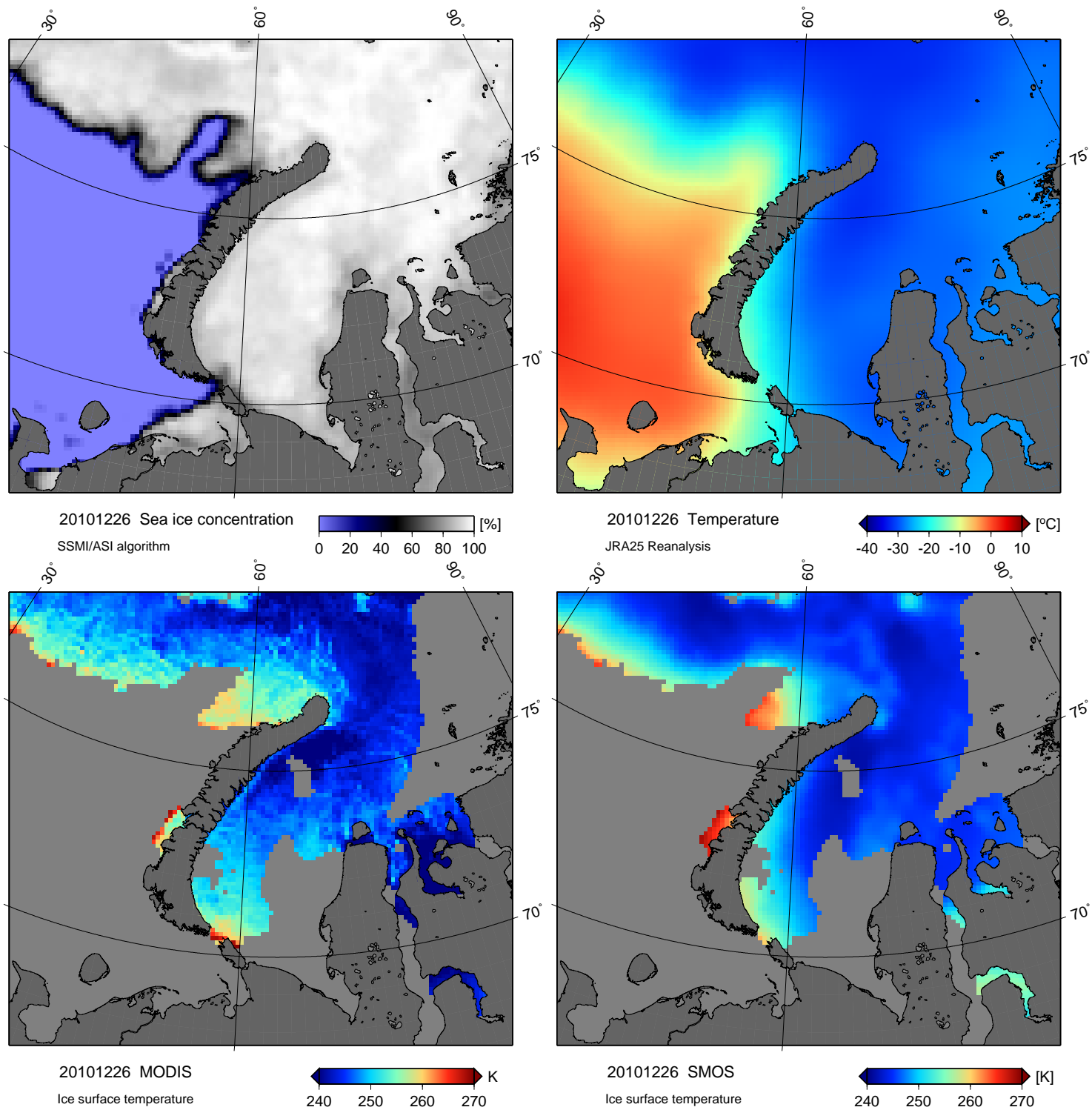

Figure 17. SSM/I ice concentration (upper left), JRA-25 surface air temperature (upper right), MODIS- and SMOS-based snow/ice surface temperature (lower left and lower right) in the Kara Sea on 26 December 2010.

with usable MODIS data. Therefore, we selected out 30 days during which the data are not badly affected by cloud coverage. Altogether, 81350 pixels are available at $12.5 \mathrm{~km}$ resolution. The histogram of the ice thicknesses (Fig. 20) shows better agreement between SMOS Algorithm II and MODIS than between SMOS Algorithm I and MODIS for these pixels. The mean ice thicknesses derived from SMOS Algorithm II and MODIS are of similar magnitude $-44 \mathrm{~cm}$ and $42 \mathrm{~cm}$, respectively, whereas SMOS Algorithm I shows $31 \mathrm{~cm}$ on average. If we restrict the comparison to the pixels with MODIS ice thicknesses less than $50 \mathrm{~cm}$, the mean ice thickness from SMOS Algorithm II is about $13 \mathrm{~cm}$ higher than the MODIS mean value (see Table 2). The spatial correlation co- efficient between SMOS and MODIS is on average about 0.6 for the selected days.

\section{Conclusions}

In this study, we develop a new SMOS sea ice thickness retrieval algorithm (denoted as Algorithm II), in which we take into account variations of ice temperature $T_{\text {ice }}$ and salinity $S_{\text {ice }}$. These are estimated during the ice thickness retrieval from the surface air temperature $T_{\mathrm{a}}$ of atmospheric reanalysis data and a model-based SSS climatology as boundary conditions. Ice thicknesses retrieved from Algorithm II are compared with that from an earlier semi-empirical algorithm 

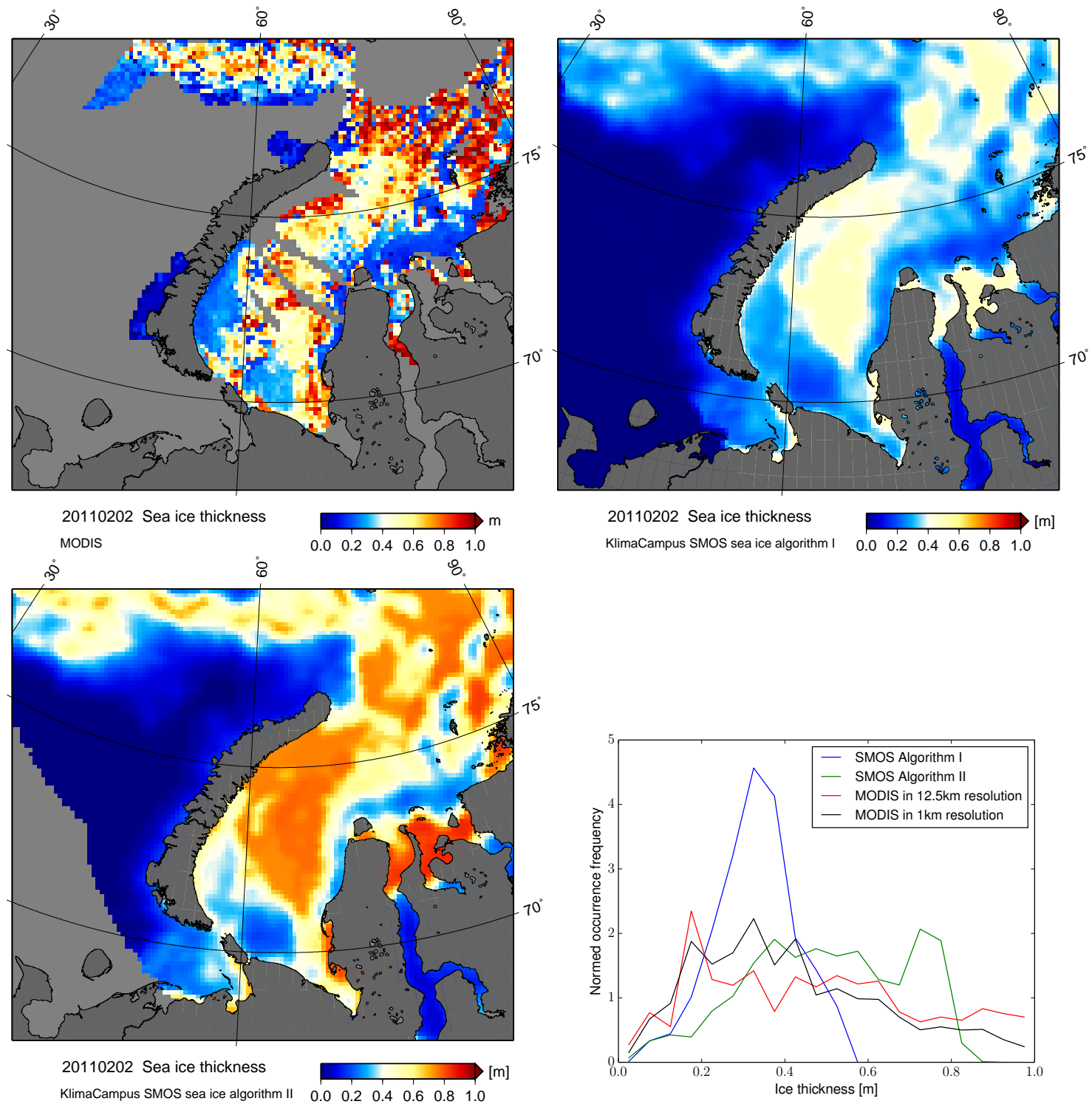

Figure 18. The modal MODIS ice thickness in $12.5 \mathrm{~km}$ grid resolution (upper left), SMOS ice thicknesses retrieved from Algorithm I (upper right) and II (lower left), and the histogram of the three ice thickness data (lower right) in the Kara Sea on 2 February 2011.

(Algorithm I) (Kaleschke et al., 2012), in which a constant $T_{\text {ice }}\left(-7^{\circ} \mathrm{C}\right)$ and $S_{\text {ice }}\left(8 \mathrm{~g} \mathrm{~kg}^{-1}\right)$ are assumed. The new algorithm allows the retrieval of considerably higher thicknesses for cold conditions and less saline ice. The maximal retrievable ice thickness $d_{\max }$ can be estimated based on the $T_{\text {ice }}$ and $S_{\text {ice }}$ at each pixel. In contrast, we estimate $d_{\max }$ to about $0.5 \mathrm{~m}$ as a constant upper limit for the ice thickness retrieval with Algorithm I. In Algorithm II, $d_{\max }$ varies from a few centimeters to about $1 \mathrm{~m}$, depending on the $T_{\text {ice }}$ and $S_{\text {ice. }}$ A TB saturation factor is defined as the ratio of $d_{\text {ice }}$ to $d_{\text {max }}$ for each pixel. A saturation ratio close to $100 \%$ indicates that the retrieved ice thickness must be considered as a minimum ice thickness and that the upper bounds of uncertainty cannot be constrained by the SMOS measurement alone.
Natural sea ice exhibits a broad range of ice thicknesses within the SMOS spatial resolution due to ice deformation. Algorithm II is based on an emissivity model including a plane layer geometry, which is not an adequate assumption for natural sea ice. Therefore, Algorithm II is statistically corrected, assuming that the thickness of natural sea ice follows a lognormal distribution. This version of the retrieval is denoted as Algorithm II*. The statistical correction factor depends on $T_{\text {ice }}$ and $S_{\text {ice }}$. For warm saline ice, the correction factor is higher than for cold, less saline ice. The corrected ice thickness is on average about twice as large compared to the plane layer assumption, which is similar to the general relation between modal and mean ice thickness. 

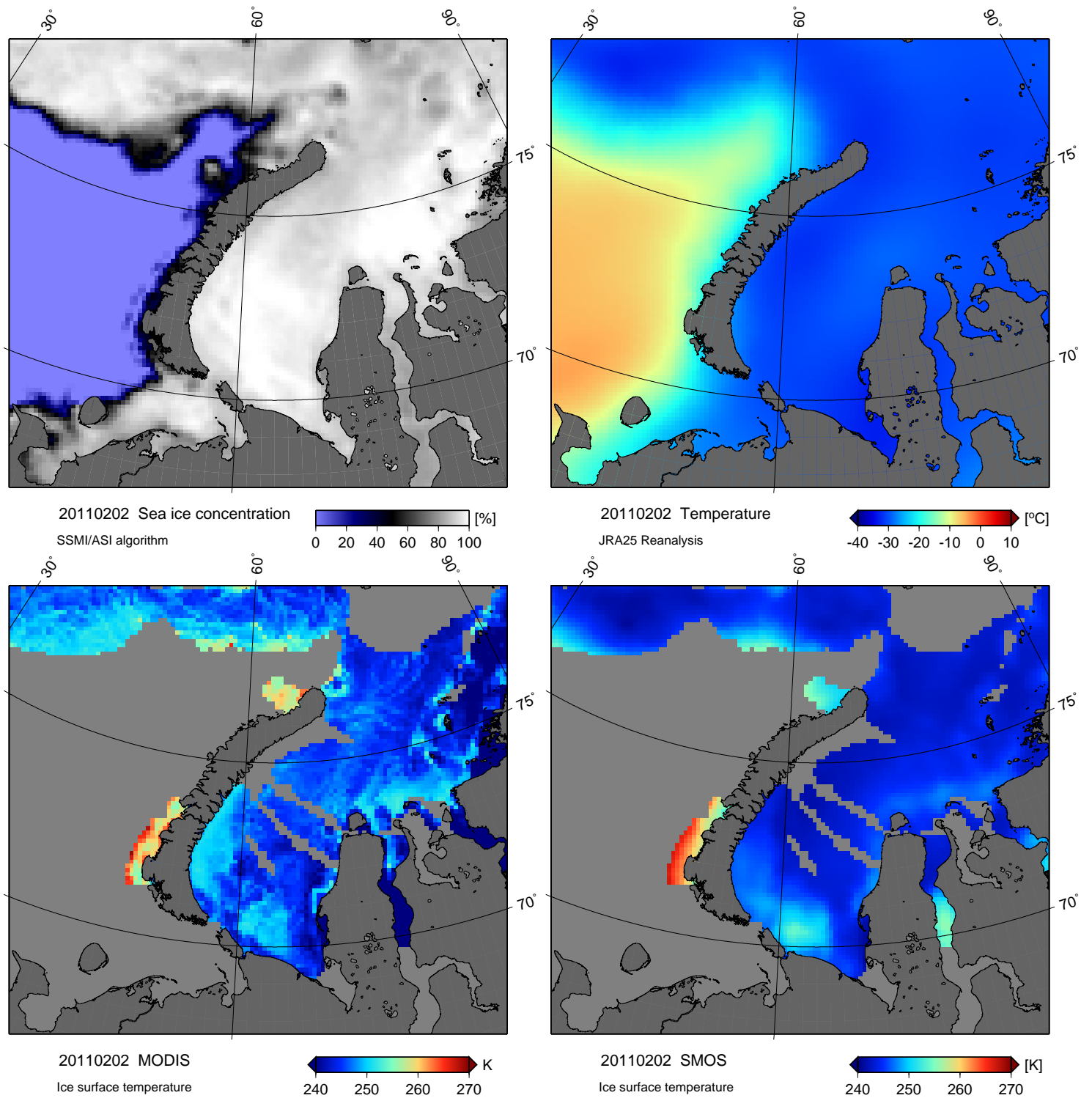

Figure 19. SSM/I ice concentration (upper left), JRA-25 surface air temperature (upper right), MODIS- and SMOS-based snow/ice surface temperature (lower left and lower right) in the Kara Sea on 2 February 2011.

The ice thickness from Algorithm II* agrees well with those from the assimilation systems TOPAZ and PIOMAS in the three months after the first occurrence of sea ice. However, from March to April, TOPAZ and PIOMAS have much higher ice thicknesses compared to the SMOS retrieval. The discrepancy coincides with the onset of surface warming. We observe a strong impact of $T_{\text {ice }}$ on the ice thickness retrieval when TB approaches saturation. The emissivity model used here does not correctly account for vertical gradients of temperature and salinity. The invalid assumption of a vertically homogeneous ice layer introduces significant uncertainties because the relative brine volume and thus the permittivity depends on ice temperature and salinity (Maaß, 2013a). More work has to be done to develop and test parameterizations that could account for the effects of a vertically structured sea ice cover to further improve the emissivity model. However, a validation with EM-Bird measurements in the polynya areas of the Laptev Sea in April 2012 shows very good agreement between EM-Bird and SMOS ice thicknesses, whereas TOPAZ and PIOMAS overestimate the ice thickness by $0.5-$ $2 \mathrm{~m}$.

For further verification, we compare our retrieval results with ice thickness derived from MODIS thermal infrared data for the Kara Sea for several clear sky occasions. The MODIS retrieval relies on a similar plane layer assumption as Algorithm I and II and represents the modal ice thickness. Because of the much larger footprint of SMOS $(\sim 40 \mathrm{~km})$ compared to MODIS $(1 \mathrm{~km})$ we aggregate the 


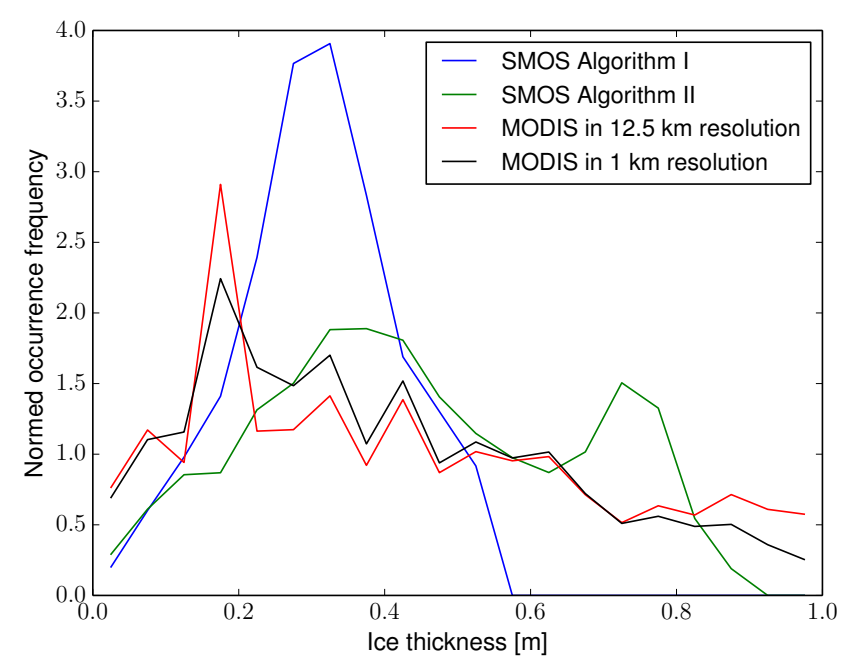

Figure 20. Histogram of SMOS (Algorithm I and II) and MODIS (in $12.5 \mathrm{~km}$ and $1 \mathrm{~km}$ grid resolution) ice thicknesses from all pixels of the selected 30 days between 2009 and 2011.

MODIS retrievals on the SMOS grid by taking the modal mean. The different integration times (SMOS: daily averages vs. MODIS: single overpasses) introduce additional uncertainties. Nevertheless, the ice thicknesses retrieved from SMOS and MODIS are very similar, with a considerably better agreement between SMOS Algorithm II and MODIS. The correlation coefficient $R$ between SMOS and MODIS data is about 0.6 for both Algorithm I and II.

The retrieval uncertainty is dominated by inaccurate assumptions and boundary conditions obtained from auxiliary data, whereas the radiometric accuracy is well constrained and sufficient, except for RFI-affected areas. Factors that affect the ice thickness retrieval include the ice concentration, ice salinity, ice temperature, snow thickness as well as the statistical thickness distribution function. Sea ice concentration data available from passive microwave sensors like the Special Sensor Microwave Imager/Sounder (SSMIS) and the Advanced Microwave Scanning Radiometer 2 (AMSR2) have an inherent uncertainty of about $2.5-5 \%$ over highconcentration ice in winter and have strong limitations in new-ice areas (Andersen et al., 2007; Ezraty, 2002). Thus, we do not correct for varying ice concentration because this would considerably increase the noise and raise as of yet unresolved problems in regions where new ice is not detected with traditional methods but only with SMOS. The variability of the sea surface salinity contributes only a little to the overall uncertainty except for low-salinity areas. By ignoring the growth-rate dependent salt inclusion in Ryvlin's parameterization, we introduce additional errors that can not be quantified without the use of more advanced sea ice thermodynamic models (Notz and Worster, 2009; Vancoppenolle et al., 2006). The radiation model used in this study is adapted from Menashi et al. (1993), which is a simple one- layer model without a snow layer. Although we consider the insulation effect of snow, the radiative contribution of the snow layer to the overall brightness temperature is ignored. This effect is investigated in Maaß et al. (2013b) with another radiation model based on Burke et al. (1979). The quantification of the effect and uncertainty caused by snow layers is considered as future work.

MODIS-based thin ice thickness retrieval is heavily restricted by clouds and distinguishing clear sky from clouds is nowhere more difficult than in winter nighttime conditions (Frey et al., 2008). Manual methods are typically needed to improve detection of thin clouds and ice fog (Maekynen et al., 2013). Distinct advantages of the SMOS sea ice thickness retrieval are the daily coverage, independent of clouds, and the large sensitivity for thin ice. Thus, our SMOS product is complementary to the sea ice thickness derived from CryoSat-2 and feasible for operational usage. However, the thickness retrieval is strictly limited to cold periods and not applicable during late spring and summer. Daily SMOS ice thickness charts from 15 October to 15 April from 2010 on are available via http://icdc.zmaw.de.

Acknowledgements. This work was funded through ESA's Support to Science Element Program under contract 4000101476. The authors would like to thank the members of the ESA SMOSIce project for helpful discussions. EM-Bird thickness measurements were conducted by the Alfred Wegener Institute for Polar and Marine Research (Thomas Krumpen and Valeria Selyuzhenok) within the Transdrift XX campaign in the framework of Russian-German research cooperation. JRA-25 reanalysis data are provided by the Japanese Meteorological Agency (JMA), the sea ice concentration data are provided by ICDC University of Hamburg, TOPAZ data are provided by Laurant Bertino from the Nansen Environmental and Remote Sensing Center in Norway, and PIOMAS data are provided by Jinlun Zhang from the University of Washington. The authors would like to thank two anonymous reviewers and the editor for their constructive comments.

Edited by: J. Stroeve

\section{References}

Andersen, S., Tonboe, R., Kaleschke, L., Heygster, G., and Pedersen, L.: Intercomparison of passive microwave sea ice concentration retrievals over the high-concentration Arctic sea ice, J. Geophys. Res., 112, C08004, doi:10.1029/2006JC003543, 2007.

Antonov, J., Seidov, D., Boyer, T., Locarnini, R., Mishonov, A., Garcia, H., Baranova, O., Zweng, M., and Johnson, D.: World Ocean Atlas 2009, Vol. 2, Salinity, edited by: Levitus, S., 184 pp., US Gov. Print. Off., Washington, DC, 2010.

Bartels-Rausch, T., Bergeron, V., Cartwright, J. H., Escribano, R., Finney, J. L., Grothe, H., Gutiérrez, P. J., Haapala, J., Kuhs, W. F., Pettersson, J. B., Price, S. D., Ignacio Sainz-Diaz, C., Stokes, D. J., Strazzulla, G., Thomson, E. S., Trinks, H., and Uras-Aytemiz, N.: Ice structures, patterns, and processes: a view across the icefields, Rev. Mod. Phys., 84, 885-944, 2012. 
Bertino, L. and Lisæter, K. A.: The TOPAZ monitoring and prediction system for the Atlantic and Arctic Oceans, Journal of Operational Oceanography, 1, 15-19, 2008.

Brath, M., Scharffenberg, M. G., Serra, N., and Stammer, D.: Altimeter-based estimates of eddy variability and eddy transports in the subpolar North Atlantic, Mar. Geod., 33, 472-503, 2010.

Burke, W., Schmugge, T., and Paris, J.: Comparison of 2.8-and 21$\mathrm{cm}$ microwave radiometer observations over soils with emission model calculations, J. Geophys. Res., 84, 287-294, 1979.

Camps, A., Vall-llossera, N., Duffo, N., Torres, F., and Corbella, I.: Performance of sea surface salinity and soil moisture retrieval algorithms with different auxiliary datasets in 2-D L-band aperture synthesis interferometric radiometers, IEEE T. Geosci. Remote, 43, 1189-1200, doi:10.1109/TGRS.2004.842096, 2005.

Camps, A., Gourrion, J., Tarongi, J., Gutierrez, A., Barbosa, J., and Castro, R.: RFI Analysis in SMOS Imagery, in: Geoscience and Remote Sensing Symposium (IGRASS proceedings 2010, 20072010, 2010.

Cox, G. and Weeks, W.: Equations for determining the gas and brine volumes in sea-ice samples, J. Glaciol., 29, 306-316, 1983.

Dee, D. P., Uppala, S. M., Simmons, A. J., Berrisford, P., Poli, P., Kobayashi, S., Andrae, U., Balmaseda, M. A., Balsamo, G., Bauer, P., Bechtold, P., Beljaars, A. C. M., van de Berg, L., Bidlot, J., Bormann, N., Delsol, C., Dragani, R., Fuentes, M., Geer, A. J., Haimberger, L., Healy, S. B., Hersbach, H., Hólm, E. V., Isaksen, L., Kållberg, P., Köhler, M., Matricardi, M., McNally, A. P., Monge-Sanz, B. M., Morcrette, J.-J., Park, B.-K., Peubey, C., de Rosnay, P., Tavolato, C., Thépaut, J.-N., and Vitart, F.: The ERA-Interim reanalysis: configuration and performance of the data assimilation system, Q. J. Roy. Meteorol. Soc., 137, 553597, doi:10.1002/qj.828, 2011.

Dmitrenko, I. A., Kirillov, S. A., Ivanov, V. V., Rudels, B., Serra, N., and Koldunov, N. V.: Modified Halocline Water over the Laptev Sea Continental Margin: Historical Data Analysis, J. Climate, 25, 5556-5565, 2012.

Doronin, Y.: Thermal interaction of the atmosphere and the hydrosphere in the Arctic, CoronetBooks, Philadelphia, 1971.

Drucker, R., Martin, S., and Moritz, R.: Observations of ice thickness and frazil ice in the St. Lawrence Island polynya from satellite imagery, upward looking sonar, and salinity/temperature moorings, J. Geophys. Res.-Oceans, 108, 3149, doi:10.1029/2001JC001213, 2003.

Erlingsson, B.: Two-dimensional deformation patterns in sea ice, J. Glaciol., 34, 301-308, 1988.

Ezraty, R.: Detection and monitoring of new-ice in the East Greenland Sea using the SeaWinds scatterometer, Journal of Ocean University of Qingdao, 1, 109-118, doi:10.1007/s11802-0020002-z, 2002.

Fekete, B. M., Vörösmarty, C. J., and Grabs, W.: Global, composite runoff fields based on observed river discharge and simulated water balances, Report 22, Global Runoff Data Centre, Federal Institute of Hydrology, Koblenz, Germany, 1999.

Frey, R. A., Ackerman, S. A., Liu, Y., Strabala, K. I., Zhang, H., Key, J. R., and Wang, X.: Cloud detection with MODIS. Part I: Improvements in the MODIS cloud mask for collection 5, J. Atmos. Ocean. Tech., 25, 1057-1072, 2008.

Godlovitch, D., Monahan, A., and Flato, G.: An idealised stochastic model of sea ice thickness dynamics, Cold. Reg. Sci. Technol., 78, 14-30, 2012.
Haas, C., Lobach, J., Hendricks, S., Rabenstein, L., and Pfaffling, A.: Helicopter-borne measurements of sea ice thickness, using a small and lightweight, digital EM system, J. Appl. Geophys., 67, 234-241, 2009.

Hall, D., Key, J., Casey, K., Riggs, G., and Cavalieri, D.: Sea ice surface temperature product from MODIS, IEEE T. Geosci. Remote, 42, 1076-1087, 2004.

Hwang, B. J., Ehn, J. K., Barber, D. G., Galley, R., and Grenfell, T. C.: Investigations of newly formed sea ice in the Cape Bathurst polynya: 2. Microwave emission, J. Geophys. Res.-Oceans, 112, C05003, doi:10.1029/2006JC003703, 2007.

Janssen, F., Schrum, C., and Backhaus, J.: A climatological data set of temperature and salinity for the Baltic Sea and the North Sea, Deutsche Hydrographische Zeitschrift, 51, 5-245, 1999.

Kaellen, E.: HIRLAM Documentation Manual, System 2.5. Swed. Meteorol. and Hydrol. Inst., Norrkoeping, Sweden, 1996, 1996.

Kaleschke, L., Maaß, N., Haas, C., Hendricks, S., Heygster, G., and Tonboe, R. T.: A sea-ice thickness retrieval model for $1.4 \mathrm{GHz}$ radiometry and application to airborne measurements over low salinity sea-ice, The Cryosphere, 4, 583-592, doi:10.5194/tc-4583-2010, 2010.

Kaleschke, L., Tian-Kunze, X., Maaß, N., Mäkynen, M., and Drusch, M.: Sea ice thickness retrieval from SMOS brightness temperatures during the Arctic freeze-up period, Geophys. Res. Lett., 39, L05501, doi:10.1029/2012GL050916, 2012.

Kaleschke, L., Tian-Kunze, X., Maass, N., Heygster, G., Huntermann, M., Wang, H., Hendricks, S., Krumpen, T., Tonboe, R., Maekynen, M., and Haas, C.: SMOS Sea Ice Retrieval Study (SMOSIce) Final Report. ESA ESTEC Contract No.:400101476/10/NL/CT, Tech. Rep., ESA ESTEC, 2013.

Kerr, Y., Waldteufel, P., Wigneron, J., Martinuzzi, J., Font, J., and Berger, M.: Soil moisture retrieval from space: The Soil Moisture and Ocean Salinity (SMOS) mission, IEEE T. Geosci. Remote, 39, 1729-1735, 2001.

Key, J. and McLaren, A.: Fractal nature of the sea ice draft profile, Geophys. Res. Lett., 18, 1437-1440, 1991.

Kovacs, A.: Sea Ice. Part 1. Bulk Salinity Versus Ice Floe Thickness, Tech. Rep., DTIC Document, 1996.

Kurtz, N. T., Farrell, S. L., Studinger, M., Galin, N., Harbeck, J. P., Lindsay, R., Onana, V. D., Panzer, B., and Sonntag, J. G.: Sea ice thickness, freeboard, and snow depth products from Operation IceBridge airborne data, The Cryosphere, 7, 1035-1056, doi:10.5194/tc-7-1035-2013, 2013.

Kwok, R. and Cunningham, G.: ICESat over Arctic sea ice: Estimation of snow depth and ice thickness, J. Geophys. Res., 113, C08010, doi:10.1029/2008JC004753, 2008.

Launiainen, J. and Cheng, B.: Modelling of ice thermodynamics in natural water bodies, Cold. Reg. Sci. Technol., 27, 153-178, 1998.

Laxon, S., Peacock, N., and Smith, D.: High interannual variability of sea ice thickness in the Arctic region, Nature, 425, 947-950, 2003.

Laxon, S. W., Giles, K. A., Ridout, A. L., Wingham, D. J., Willatt, R., Cullen, R., Kwok, R., Schweiger, A., Zhang, J., Haas, C., Hendricks, S., Krishfield, R., Kurtz, N., Farrell, S., and Davidson, M.: CryoSat-2 estimates of Arctic sea ice thickness and volume, Geophys. Res. Lett., 40, 732-737, doi:10.1002/grl.50193, 2013.

Locarnini, R., Mishonov, A., Antonov, J., Boyer, T., Garcia, H., Baranova, O., Zweng, M., and Johnson, D.: World Ocean Atlas 
2009, vol. 1, Temperature, NOAA Atlas NESDIS, Report 68, US Government Printing Office, Washington, D.C., 184 pp., 2010.

Maaß, N.: Remote sensing of sea ice thickness using SMOS data, Reports on Earth System Science, available at: http://www.mpimet.mpg.de/fileadmin/publikationen/Reports/ WEB_BzE_131.pdf (last access: 26 May 2014), 2013a.

Maaß, N., Kaleschke, L., Tian-Kunze, X., and Drusch, M.: Snow thickness retrieval over thick Arctic sea ice using SMOS satellite data, The Cryosphere, 7, 1971-1989, doi:10.5194/tc-7-19712013, 2013b.

Maekynen, M., Cheng, B., and Similae, M.: On the accuracy of thin-ice thickness retrieval using MODIS thermal imagery over Arctic first-year ice, Ann. Glaciol., 62, 87-96, doi:10.3189/2013AoG62A166, 2013.

Marshall, J., Adcroft, A., Hill, C., Perelman, L., and Heisey, C.: A finite-volume, incompressible Navier Stokes model for studies of the ocean on parallel computers, J. Geophys. Res., 102, 57535766, 1997.

Martin, S., Drucker, R., Kwok, R., and Holt, B.: Improvements in the estimates of ice thickness and production in the Chukchi Sea polynyas derived from AMSR-E, Geophys. Res. Lett., 32, L05505, doi:10.1029/2004GL022013, 2005.

Maykut, G. A.: Geophysics of Sea Ice, chap. The surface heat and mass balance, 395-463, Plenum, New York, 1986.

Mecklenburg, S., Drusch, M., Kerr, Y. H., Font, J., Martin-Neira, M., Delwart, S., Buenadicha, G., Reul, N., Daganzo-Eusebio, E., Oliva, R., and Crapolicchio, R.: ESA's soil moisture and ocean salinity mission: mission performance and operations, IEEE T. Geosci. Remote, 50, 1354-1366, 2012.

Menashi, J., Germain, K., Swift, C., Comiso, J., and Lohanick, A.: Low-frequency passive-microwave observations of sea ice in the Weddell Sea, J. Geophys. Res., 98, 22569-22577, 1993.

Naoki, K., Ukita, J., Nishio, F., Nakayama, M., Comiso, J. C., and Gasiewski, A.: Thin sea ice thickness as inferred from passive microwave and in situ observations, J. Geophys. Res., 113, C02S16, doi:10.1029/2007JC004270, 2008.

Nihashi, S., Ohshima, K. I., Tamura, T., Fukamachi, Y., and Saitoh, S.-I.: Thickness and production of sea ice in the Okhotsk Sea coastal polynyas from AMSR-E, J. Geophys. Res.-Oceans, 114, C10025, doi:10.1029/2008JC005222, 2009.

Notz, D. and Worster, M. G.: Desalination processes of sea ice revisited, J. Geophys. Res.-Oceans, 114, C05006, doi:10.1029/2008JC004885, 2009.

NSIDC: Morphometric characteristics of ice and snow in the Arctic Basin: aircraft landing observations from the Former Soviet Union, 1928-1989, compiled by Romanov I. P., Boulder, CO: National Snow and Ice Data Center, Digital media, 2004.

Onogi, K., Tslttsui, J., Koide, H., Sakamoto, M., Kobayashi, S., Hatsushika, H., Matsumoto, T., Yamazaki, N., Kaalhori, H., Takahashi, K., Kadokura, S., Wada, K., Kato, K., Oyama, R., Ose, T., Mannoji, N., and Taira, R.: The JRA-25 reanalysis, J. Meteorol. Soc. Jpn., 85, 369-432, 2007.

Perovich, D. K. and Elder, B. C.: Temporal evolution of Arctic seaice temperature, Ann. Glaciol., 33, 207-211, 2001.

Pfaffling, A., Haas, C., and Reid, J. E.: Direct helicopter EM-Seaice thickness inversion assessed with synthetic and field data, Geophysics, 72, F127-F137, 2007.

Pinori, S., Crapolicchio, R., and Mecklenburg, S.: Preparing the ESA-SMOS (soil moisture and ocean salinity) mission-overview of the user data products and data distribution strategy, in: Microwave Radiometry and Remote Sensing of the Environment, MICRORAD, 1-4, IEEE, 2008.

Ryvlin, A. I.: Method of forecasting flexural strength of an ice cover, Probl. Arct. Antarct., 45, 79-86, 1974.

Serra, N., Käse, R. H., Köhl, A., Stammer, D., and Quadfasel, D. On the low-frequency phase relation between the Denmark Strait and the Faroe-Bank Channel overflows, Tellus A, 62, 530-550, doi:10.1111/j.1600-0870.2010.00445.x, 2010.

Singh, R. K., Oza, S. R., Vyas, N. K., and Sarkar, A.: Estimation of thin ice thickness from the advanced microwave scanning radiometer-EOS for coastal polynyas in the Chukchi and Beaufort Seas, IEEE T. Geosci. Remote, 49, 2993-2998, 2011.

Smith, W. H. and Sandwell, D. T.: Global sea floor topography from satellite altimetry and ship depth soundings, Science, 277, 19561962, 1997.

Steele, M., Morley, R., and Ermold, W.: PHC: A global ocean hydrography with a high-quality Arctic Ocean, J. Climate, 14, 2079-2087, 2001.

Tamura, T. and Ohshima, K. I.: Mapping of sea ice production in the Arctic coastal polynyas, J. Geophys. Res.-Oceans, 116, C07030, doi:10.1029/2010JC006586, 2011.

Tamura, T., Ohshima, K. I., Markus, T., Cavalieri, D. J., Nihashi, S., and Hirasawa, N.: Estimation of thin ice thickness and detection of fast ice from SSM/I data in the Antarctic Ocean, J. Atmos. Ocean. Tech., 24, 1757-1772, doi:10.1175/JTECH2113.1, 2007.

Tan, B., Li, Z.-j., Lu, P., Haas, C., and Nicolaus, M.: Morphology of sea ice pressure ridges in the northwestern Weddell Sea in winter, J. Geophys. Res.-Oceans, 117, C06024, doi:10.1029/2011JC007800, 2012.

Thorndike, A.: Estimates of sea ice thickness distribution using observations and theory, J. Geophys. Res., 97, 12601-12612, 1992.

Thorndike, A., Rothrock, D., Maykut, G., and Colony, R.: The thickness distribution of sea ice, J. Geophys. Res., 80, 45014513, 1975.

Unden, P. E. A.: HIRLAM-5 scientific documentation, Swed. Meteorol. and Hydrol. Inst., Norrkoeping, Sweden, 2002.

Untersteiner, N.: Calculations of temperature regime and heat budget of sea ice in the Central Arctic, J. Geophys. Res., 69, 47554766, 1964.

Vancoppenolle, M., Fichefet, T., and Bitz, C. M.: Modeling the salinity profile of undeformed Arctic sea ice, Geophys. Res. Lett., 33, L21501, doi:10.1029/2006GL028342, 2006.

Vant, M., Ramseier, R., and Makios, V.: The complex-dielectric constant of sea ice at frequencies in the range $0.1-40 \mathrm{GHz}, \mathrm{J}$. Appl. Phys., 49, 1264-1280, 1978.

Wang, X., Key, J. R., and Liu, Y.: A thermodynamic model for estimating sea and lake ice thickness with optical satellite data, J. Geophys. Res.-Oceans, 115, C12035, doi:10.1029/2009JC005857, 2010.

Warren, S. G., Rigor, I. G., Untersteiner, N., Radionov, V. F., Bryazgin, N. N., Aleksandrov, Y. I., and Colony, R.: Snow depth on Arctic sea ice, J. Climate, 12, 1814-1829, 1999.

Yu, Y. and Rothrock, D.: Thin ice thickness from satellite thermal imagery, J. Geophys. Res., 101, 25753-25766, 1996.

Zhang, J. and Rothrock, D.: Modeling global sea ice with a thickness and enthalpy distribution model in generalized curvilinear coordinates, Mon. Weather Rev., 131, 845-861, 2003. 